\title{
Chemical complexity in the Horsehead Photo-Dissociation Region
}

\author{
Viviana V. Guzmán ${ }^{a}$, Jérôme Pety ${ }^{a, b}$, Pierre Gratier ${ }^{a, b}$, Javier R. Goicoechea ${ }^{c}$, Maryvonne \\ Gerin $^{b}$, Evelyne Roueff ${ }^{d}$, Franck Le Petit ${ }^{d}$ and Jacques Le Bourlot ${ }^{d}$
}

Received 29th November 2013, Accepted 23th January 2014

DOI: $10.1039 / \mathrm{c3fd00114h}$

The interstellar medium is known to be chemically complex. Organic molecules with up to 11 atoms have been detected in the interstellar medium, and are believed to be formed on the ices around dust grains. The ices can be released into the gas-phase either through thermal desorption, when a newly formed star heats the medium around it and completely evaporates the ices; or through non-thermal desorption mechanisms, such as photodesorption, when a single far-UV photon releases only a few molecules from the ices. The first one dominates in hot cores, hot corinos and strongly UV-illuminated PDRs, while the second one dominates in colder regions, such as low UV-field PDRs. This is the case of the Horsehead were dust temperatures are $\simeq 20-30 \mathrm{~K}$, and therefore offers a clean environment to investigate what is the role of photodesorption. We have carried-out an unbiased spectral line survey at 3,2 and $1 \mathrm{~mm}$ with the IRAM-30m telescope in the Horsehead nebula, with an unprecedented combination of bandwidth, high spectral resolution and sensitivity. Two positions were observed: the warm PDR and a cold condensation shielded from the UV field (dense core), located just behind the PDR edge. We summarize our recently published results from this survey and present the first detection of the complex organic molecules $\mathrm{HCOOH}, \mathrm{CH}_{2} \mathrm{CO}, \mathrm{CH}_{3} \mathrm{CHO}$ and $\mathrm{CH}_{3} \mathrm{CCH}$ in a PDR. These species together with $\mathrm{CH}_{3} \mathrm{CN}$ present enhanced abundances in the PDR compared to the dense core. This suggests that photodesorption is an efficient mechanism to release complex molecules into the gas-phase in far-UV illuminated regions.

\section{Introduction}

Molecular lines are used to trace the structure of the interstellar medium (ISM) and the physical conditions of the gas in different environments, from high-z galaxies to proto-planetary disks. However, the interpretation of molecular observations for most of these objects is hampered by the complex source geometries, and the small angular sizes in the sky compared with the angular resolution of current instrumentation, that prevent us from resolving the different gas components, and hence to know which specific region each molecule actually traces. Therefore, in order to fully benefit from the diagnostic power of the molecular lines, the formation and destruction paths of the molecules must be quantitatively understood. This challenging task requires the contribution of theoretical models, laboratory experiments and observations. Well-defined sets of observations of simple template sources are key to benchmark the predictions of theoretical models. In this respect, the Horsehead nebula has proven to be a good template source of low-UV field irradiated environments because it is close-by ( $\sim 400 \mathrm{pc})$, it has a simple geometry (edge-on) and its gas density is well constrained. Moreover, in contrast to other Galactic photo-dissociation regions (PDRs), like the Orion Bar and Mon R2 which present large radiation fields $\left(\chi \simeq 10^{4}-10^{5}\right)$, the Horsehead is illuminated by a weaker radiation field $(\chi \sim 60)$ and thus better resembles the majority of the far-UV illuminated neutral gas in the Galaxy. Furthermore, the dust grains in the Horsehead have temperatures of $\simeq 20-30 \mathrm{~K}$, which is not enough to thermally desorb most of the ices. The Horsehead therefore offers a clean environment to isolate the role of photo-desorption of ices on dust grains.

Observations by the Infrared Space Observatory (ISO) and Spitzer have shown that dust grains are covered by ice mantles in the cold envelopes surrounding high-mass protostars $\frac{1,2}{}$, low-mass protostars ${ }^{3-6}$ and in isolated dense cores ${ }^{7}$. These studies revealed that the ice mantles consist mostly of $\mathrm{H}_{2} \mathrm{O}, \mathrm{CO}_{2}$ and $\mathrm{CO}$, with smaller amounts of $\mathrm{CH}_{3} \mathrm{OH}, \mathrm{CH}_{4}, \mathrm{NH}_{3}$ and $\mathrm{H}_{2} \mathrm{CO}$. More complex prebiotic molecules, such as glycine $\left(\mathrm{NH}_{2} \mathrm{CH}_{2} \mathrm{COOH}\right)$ could also form on the ices around dust grains. Although their exact formation is unclear, it is believed that the simplest prebiotic molecules have an interstellar origin $\frac{8.9}{}$. Indeed, numerous amino acids, which are the building blocks of proteins, have been found in meteorites 10 . In addition, glycine, which is the simplest amino acid, has been detected in samples returned by NASA's Stardust spacecraft from comet Wild $2 \stackrel{11}{2}$. Despite controversial detection

\footnotetext{
${ }^{a}$ IRAM, 300 rue de la Piscine, 38406 Saint Martin d'Her̀es, France. E-mail: vguzman@cfa.harvard.edu

${ }^{b}$ LERMA-LRA, UMR 8112, Observatoire de Paris and École normale Supérieure, 24 rue Lhomond, 75231 Paris, France

${ }^{c}$ Centro de Astrobiología, CSIC-INTA, Carretera de Ajalvir, Km 4, Torrejón de Ardoz, 28850 Madrid, Spain

${ }^{d}$ LUTH UMR 8102, CNRS and Observatoire de Paris, Place J. Janssen, 92195 Meudon Cedex, France
} 
Table 1 Observation parameters for the maps shown in Figs. 1 The projection center of the maps is $\alpha_{2000}=05^{h} 40^{m} 54.27^{s}$, $\delta_{2000}=-02^{\circ} 28^{\prime} 00^{\prime \prime}$.

\begin{tabular}{|c|c|c|c|c|c|c|c|c|c|}
\hline Molecule & Transition & $\begin{array}{r}\text { Frequency } \\
\mathrm{GHz} \\
\end{array}$ & Instrument & $\begin{array}{l}\text { Beam } \\
\text { arcsec }\end{array}$ & $\underset{\circ}{\mathrm{PA}}$ & $\begin{array}{c}\text { Int. Time } \\
\text { hours }\end{array}$ & $\begin{array}{c}T_{\text {sys }} \\
\mathrm{K}\left(T_{\mathrm{A}}^{*}\right) \\
\end{array}$ & $\begin{array}{c}\text { Noise } \\
\mathrm{K}\left(T_{\mathrm{mb}}\right)\end{array}$ & Ref. \\
\hline \multicolumn{2}{|c|}{ Continuum at $1.2 \mathrm{~mm}$} & 250.000000 & 30m/MAMBO & 11.7 & - & - & - & - & Hily-Blant et al. 19 \\
\hline $\mathrm{CCH}$ & $1,3 / 2(2)-0,1 / 2(1)$ & 87.316898 & PdBI/C\&D & $7.2 \times 5.0$ & 54 & & & & Pety et al. 20 \\
\hline $\mathrm{CH}_{3} \mathrm{CHO}$ & $5_{15}-4_{14}, 6_{16}-5_{15}$ & $93.5,112.2$ & 30m/EMIR & 30.0 & 0 & & & & This work \\
\hline $\mathrm{HCO}$ & $1_{01} 3 / 2,2-0_{00} 1 / 2,1$ & 86.670760 & $30 \mathrm{~m} / \mathrm{AB} 100$ & 29.9 & 0 & $2.6 / 5.0^{a}$ & 133 & 63 & Gerin et al. 21 \\
\hline $\mathrm{CF}^{+}$ & $1-0$ & 102.587533 & 30m/EMIR & 25.4 & 0 & 2.5 & 88 & 0.13 & Guzmán et al.22 \\
\hline $\mathrm{DCO}^{+}$ & $3-2$ & 216.112582 & 30m/HERA & 11.4 & 0 & $1.5 / 2.0^{a}$ & 230 & 0.10 & Pety et al. 23 \\
\hline $\mathrm{p}-\mathrm{H}_{2} \mathrm{CO}$ & $2_{02}-1_{01}$ & 145.602949 & 30m/EMIR & 17.8 & 0 & $7.4 / 12.9^{a}$ & 208 & 0.17 & Guzman et al. 24 \\
\hline $\mathrm{CH}_{3} \mathrm{OH}-\mathrm{A}$ & $3_{0}-2_{0}$ & 145.103152 & 30m/EMIR & 17.9 & 0 & $7.4 / 12.9^{a}$ & 208 & 0.095 & Guzman et al. ${ }^{24}$ \\
\hline
\end{tabular}

${ }^{a}$ Two values are given for the integration time: the on-source time and the telescope time.
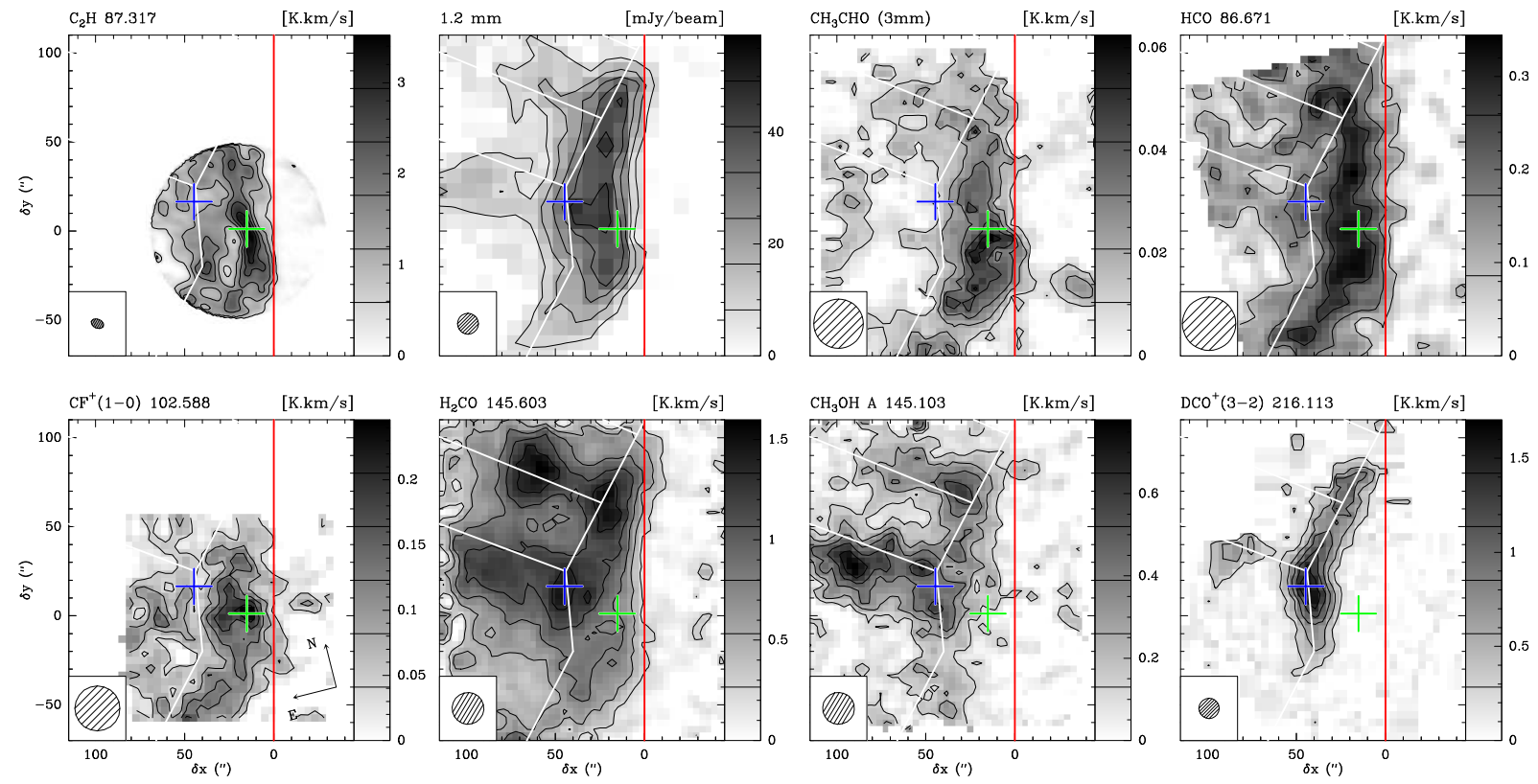

Fig. 1 IRAM-30m and PdBI maps of the Horsehead edge. Maps were rotated by $14^{\circ}$ counter-clockwise around the projection center, located at $(\delta x, \delta y)=\left(20^{\prime \prime}, 0^{\prime \prime}\right)$, to bring the exciting star direction in the horizontal direction. The horizontal zero, marked by the red vertical line, delineates the PDR edge. The crosses show the positions of the PDR (green) and the dense core (blue), where deep integrations were performed in the Horsehead WHISPER line survey (PI: J.Pety). The white lines delineate the arc-like structure of the $\mathrm{DCO}^{+}$emission. The spatial resolution is plotted in the bottom-left corner. Values of contour levels are shown in the respective image lookup table. The emission of all lines is integrated between 10.1 and $11.1 \mathrm{~km} \mathrm{~s}^{-1}$

claims $\stackrel{12-14}{-14}$, glycine or other more complex amino acids have not been detected in the interstellar medium yet. The most complex molecules detected in the interstellar medium so far, are glycolaldehyde 15 ( $\left.\mathrm{CH}_{2}(\mathrm{OH}) \mathrm{CHO}\right)$, acetamide $\frac{16}{\underline{16}}\left(\mathrm{CH}_{3} \mathrm{CONH}_{2}\right)$, aminoacetonitrile $\frac{17}{\underline{1}}\left(\mathrm{NH}_{2} \mathrm{CH}_{2} \mathrm{CN}\right)$, and the ethyl formate $\frac{18}{\underline{18}}\left(\mathrm{C}_{2} \mathrm{H}_{5} \mathrm{OCHO}\right)$. This shows the high degree of chemical complexity that can be reached in the interstellar medium.

Simpler, but still complex organic molecules, such as methanol $\left(\mathrm{CH}_{3} \mathrm{OH}\right)$, ketene $\left(\mathrm{CH}_{2} \mathrm{CO}\right)$, acetaldehyde $\left(\mathrm{CH}_{3} \mathrm{CHO}\right)$, formic acid $(\mathrm{HCOOH})$, formamide $\left(\mathrm{NH}_{2} \mathrm{CHO}\right)$, propyne $\left(\mathrm{CH}_{3} \mathrm{CCH}\right)$, methyl formate $\left(\mathrm{HCOOCH}_{3}\right)$, and dimethyl ether $\left(\mathrm{CH}_{3} \mathrm{OCH}_{3}\right)$, are widely observed in hot cores of high-mass protostars $25-27$, and also in hotcorinos of low-mass protostars 28.29 . The complex molecules observed in protostars have been classified in three different generations by Herbst and van Dishoeck $\underline{30}$, depending on their formation mechanism. The zeroth generation species form through grain surface processes in the cold $(<20 \mathrm{~K})$ pre-stellar stage (e.g., $\mathrm{H}_{2} \mathrm{CO}$ and $\left.\mathrm{CH}_{3} \mathrm{OH}\right)$. First generation species form from surface reactions between photodissociated products of the zeroth generation species in the warm-up $(20-100 \mathrm{~K})$ period. Finally, second generations species form in the hot $(>100 \mathrm{~K})$ gas from the evaporated zeroth and first generation species in the so called hot-core phase. Although it is clear that grain surface processes play an important role in the formation of complex molecules, the exact formation mechanism of most complex molecules is still debated.

Bisschop et al. .27 observed several complex molecules toward seven high-mass protostars, and classified them as cold $(\mathrm{T}<100 \mathrm{~K})$ and hot $(\mathrm{T}>100 \mathrm{~K})$ molecules based on their rotational temperatures. The hot molecules 
Table 2 Summary of abundances with respect to total hydrogen nuclei $\left(N_{\mathrm{H}}=N(\mathrm{X}) /\left(N(\mathrm{H})+2 N\left(\mathrm{H}_{2}\right)\right)\right)$ toward the PDR and dense core. The column densities of the total hydrogen nuclei are $N_{\mathrm{H}}=3.8 \times 10^{22} \mathrm{~cm}^{-2}$ (PDR) and $N_{\mathrm{H}}=6.4 \times 10^{22} \mathrm{~cm}^{-2}$ (dense core).

\begin{tabular}{|c|c|c|c|c|c|c|}
\hline \multirow[t]{2}{*}{ Species } & \multirow{2}{*}{$\begin{array}{l}\text { Beam } \\
\left({ }^{\prime \prime}\right)\end{array}$} & \multicolumn{2}{|l|}{ PDR } & \multicolumn{2}{|l|}{ Core } & \multirow[t]{2}{*}{ Ref. } \\
\hline & & Abundance & Offsets & Abundance & Offsets & \\
\hline $\mathrm{C}^{18} \mathrm{O}$ & $6.5 \times 4.3$ & $1.9 \times 10^{-7}$ & $(-6,4)$ & - & - & Pety et al. 20 \\
\hline $\mathrm{C}_{2} \mathrm{H}$ & $7.2 \times 5.0$ & $1.4 \times 10^{-8}$ & $(-6,4)$ & - & - & Pety et al. 20 \\
\hline $\mathrm{c}-\mathrm{C}_{3} \mathrm{H}$ & 28 & $2.7 \times 10^{-10}$ & $(-10,0)$ & - & - & Teyssier et al. 31 \\
\hline $1-\mathrm{C}_{3} \mathrm{H}$ & 28 & $1.4 \times 10^{-10}$ & $(-10,0)$ & - & - & Teyssier et al. 31 \\
\hline c- $-\mathrm{C}_{3} \mathrm{H}_{2}$ & $6.1 \times 4.7$ & $1.1 \times 10^{-9}$ & $(-6,4)$ & - & - & Pety et al..$^{20}$ \\
\hline $1-\mathrm{C}_{3} \mathrm{H}_{2}$ & 27 & $<4.6 \times 10^{-11}$ & $(-10,0)$ & - & - & Teyssier et al. 31 \\
\hline $\mathrm{C}_{4} \mathrm{H}$ & $6.1 \times 4.7$ & $1.0 \times 10^{-9}$ & $(-6,-4)$ & - & - & Pety et al. 20 \\
\hline $\mathrm{C}_{6} \mathrm{H}$ & 28 & $2.2 \times 10^{-11}$ & $(-6,4)$ & - & - & Agúndez et al. $\stackrel{32}{\underline{n}}$ \\
\hline $\mathrm{CS}$ & 10 & $2.0 \times 10^{-9}$ & $(4,0)$ & $2.9 \times 10^{-9}$ & $(21,15)$ & Goicoechea et al. 33 \\
\hline$C^{34} S$ & 16 & $9.2 \times 10^{-11}$ & $(4,0)$ & $9.1 \times 10^{-11}$ & $(21,15)$ & Goicoechea et al. 33 \\
\hline $\mathrm{HCS}^{+}$ & 29 & $1.7 \times 10^{-11}$ & $(4,0)$ & $1.2 \times 10^{-11}$ & $(21,15)$ & Goicoechea et al. 33 \\
\hline $\mathrm{HCO}$ & $6.7 \times 4.4$ & $8.4 \times 10^{-10}$ & $(-5,0)$ & $<8.0 \times 10^{-11}$ & $(20,22)$ & Gerin $e t$ al. 21 \\
\hline $\mathrm{HCO}^{+}$ & 28 & $9.0 \times 10^{-10}$ & $(-5,0)$ & $3.9 \times 10^{-9}$ & $(20,22)$ & Goicoechea et al. 34 \\
\hline $\mathrm{H}^{13} \mathrm{CO}^{+}$ & $6.8 \times 4.7$ & $1.5 \times 10^{-11}$ & $(-5,0)$ & $6.5 \times 10^{-11}$ & $(20,22)$ & Goicoechea et al. 34 \\
\hline $\mathrm{HOC}^{+}$ & 28 & $4.0 \times 10^{-12}$ & $(-5,0)$ & - & $(20,22)$ & Goicoechea et al. 34 \\
\hline $\mathrm{CO}^{+}$ & 10 & $<5.0 \times 10^{-13}$ & $(-5,0)$ & - & $(20,22)$ & Goicoechea et al. 34 \\
\hline $\mathrm{DCO}^{+}$ & 12 & - & $(-5,0)$ & $8.0 \times 10^{-11}$ & $(20,22)$ & Pety et al. $\underline{23}$ \\
\hline $\mathrm{CF}^{+}$ & 25 & $5.7 \times 10^{-10}$ & $(-5,0)$ & $<6.9 \times 10^{-11}$ & $(20,22)$ & Guzmán et al. 22 \\
\hline $\mathrm{C}_{3} \mathrm{H}^{+}$ & 27 & $3.1 \times 10^{-11}$ & $(-5,0)$ & - & $(20,22)$ & Pety et al. 35 \\
\hline $\mathrm{O}-\mathrm{H}_{2} \mathrm{CO}$ & $6.1 \times 5.6$ & $1.9 \times 10^{-10}$ & $(-5,0)$ & $1.5 \times 10^{-10}$ & $(20,22)$ & Guzmán et al. 36 \\
\hline $\mathrm{p}-\mathrm{H}_{2} \mathrm{CO}$ & $6.1 \times 5.6$ & $9.5 \times 10^{-11}$ & $(-5,0)$ & $5.0 \times 10^{-11}$ & $(20,22)$ & Guzmán et al. $\underline{\underline{36}}$ \\
\hline HDCO & 18 & - & $(-5,0)$ & $2.5 \times 10^{-11}$ & $(20,22)$ & Guzmán et al. 36 \\
\hline $\mathrm{D}_{2} \mathrm{CO}$ & 24 & - & $(-5,0)$ & $1.6 \times 10^{-11}$ & $(20,22)$ & Guzmán et al. 36 \\
\hline $\mathrm{CH}_{3} \mathrm{OH}-\mathrm{E}$ & $6.1 \times 5.6$ & $7.0 \times 10^{-11}$ & $(-5,0)$ & $1.0 \times 10^{-10}$ & $(20,22)$ & Guzman et al. ${ }^{24}$ \\
\hline $\mathrm{CH}_{3} \mathrm{OH}-\mathrm{A}$ & $6.1 \times 5.6$ & $5.3 \times 10^{-11}$ & $(-5,0)$ & $1.3 \times 10^{-10}$ & $(20,22)$ & Guzman et al. $\underline{\underline{24}}$ \\
\hline $\mathrm{CH}_{3} \mathrm{CN}$ & 27 & $2.5 \times 10^{-10}$ & $(-5,0)$ & $7.9 \times 10^{-12}$ & $(20,22)$ & Gratier et al. 37 \\
\hline $\mathrm{CH}_{3} \mathrm{NC}$ & 25 & $4.1 \times 10^{-11}$ & $(-5,0)$ & $<7.8 \times 10^{-12}$ & $(20,22)$ & Gratier et al. 37 \\
\hline $\mathrm{HC}_{3} \mathrm{~N}$ & 30 & $6.3 \times 10^{-12}$ & $(-5,0)$ & $7.9 \times 10^{-12}$ & $(20,22)$ & Gratier et al. 37 \\
\hline $\mathrm{t}-\mathrm{HCOOH}$ & 29 & $5.2 \times 10^{-11}$ & $(-5,0)$ & $1.4 \times 10^{-11}$ & $(20,22)$ & This work \\
\hline $\mathrm{o}-\mathrm{CH}_{2} \mathrm{CO}$ & 30 & $1.3 \times 10^{-10}$ & $(-5,0)$ & $4.2 \times 10^{-11}$ & $(20,22)$ & This work \\
\hline $\mathrm{p}-\mathrm{CH}_{2} \mathrm{CO}$ & 26 & $1.8 \times 10^{-11}$ & $(-5,0)$ & $7.3 \times 10^{-12}$ & $(20,22)$ & This work \\
\hline $\mathrm{CH}_{3} \mathrm{CHO}-\mathrm{E}$ & 27 & $1.4 \times 10^{-11}$ & $(-5,0)$ & $3.9 \times 10^{-12}$ & $(20,22)$ & This work \\
\hline $\mathrm{CH}_{3} \mathrm{CHO}-\mathrm{A}$ & 27 & $5.4 \times 10^{-11}$ & $(-5,0)$ & $2.0 \times 10^{-11}$ & $(20,22)$ & This work \\
\hline $\mathrm{CH}_{3} \mathrm{CCH}$ & 29 & $4.4 \times 10^{-10}$ & $(-5,0)$ & $3.0 \times 10^{-10}$ & $(20,22)$ & This work \\
\hline
\end{tabular}

include $\mathrm{H}_{2} \mathrm{CO}, \mathrm{CH}_{3} \mathrm{OH}, \mathrm{HNCO}, \mathrm{CH}_{3} \mathrm{CN}, \mathrm{HCOOCH}_{3}$ and $\mathrm{CH}_{3} \mathrm{OCH}_{3}$, while the cold molecules include $\mathrm{HCOOH}$, $\mathrm{CH}_{2} \mathrm{CO}, \mathrm{CH}_{3} \mathrm{CHO}$, and $\mathrm{CH}_{3} \mathrm{CCH}$. The cold molecules are expected to be present in the colder envelope around the hot-core. Öberg et al. $\stackrel{38}{\underline{3}}$ studied the spatial distribution of complex molecules around a high-mass protostar and found that $\mathrm{CH}_{2} \mathrm{CO}, \mathrm{CH}_{3} \mathrm{CHO}$ and $\mathrm{CH}_{3} \mathrm{CCH}$ are indeed abundant in the cold envelope. They classified them as zeroth order molecules because their formation must require very little heat.

Complex organic molecules may trace other environments than hot cores and hot corinos. They are also present in the cold UV-shielded gas. Bacmann et al. $\frac{39}{\underline{9}}$ detected $\mathrm{CH}_{3} \mathrm{OCH}_{3}, \mathrm{CH}_{3} \mathrm{OCHO}, \mathrm{CH}_{2} \mathrm{CO}$ and $\mathrm{CH}_{3} \mathrm{CHO}$ in a cold $\left(T_{\text {kin }} \sim 10 \mathrm{~K}\right)$ prestellar core. These observations challenged the current formation scenario of complex molecules on dust grains, because the diffusion reactions that lead to the formation of species are not efficient on dust grains with temperatures of $\sim 10 \mathrm{~K}$. $\mathrm{CH}_{3} \mathrm{CHO}$ and $\mathrm{CH}_{2} \mathrm{CO}$ have also been detected in the dark cloud TMC1 10.41 . $\mathrm{CH}_{2} \mathrm{CO}$ and $\mathrm{CH}_{3} \mathrm{CHO}$ have also been detected in a $z=0.89$ spiral galaxy located in front of the quasar PKS1830-211 12 .

In this paper, we present the results of an unbiased line survey performed with the IRAM-30m telescope in a classic star forming region, the Horsehead nebula. We describe the observations in section 2 In section 3 we present a summary of the recently published results of the line survey. In section 4 we present new unpublished results about the first detection of complex molecules in a PDR. We discuss these observations in section 5 and 


\section{Observations}

\subsection{Deep pointed integrations: The Horsehead WHISPER line survey}

With the purpose of providing a benchmark to chemical models we have performed a complete and unbiased line survey: the Horsehead WHISPER (Wideband High-resolution Iram-30m Surveys at two Positions with Emir Receivers, PI: J. Pety). Two positions were observed: 1) the HCO peak, which is characteristic of the photodissociation region at the surface of the Horsehead nebula ${ }^{21}$, and 2) the $\mathrm{DCO}^{+}$peak, which belongs to a cold condensation located less than $40^{\prime \prime}$ away from the PDR edge, where $\mathrm{HCO}^{+}$and other species are highly deuterated $^{23}$. Hereafter we refer to these two positions as the PDR and dense core, respectively. The combination of the new EMIR receivers at the IRAM-30m telescope and the Fourier transform spectrometers (FTS) yields a spectral survey with unprecedented combination of bandwidth $(36 \mathrm{GHz}$ at $3 \mathrm{~mm}, 34 \mathrm{GHz}$ at $2 \mathrm{~mm}$ and $73 \mathrm{GHz}$ at $1 \mathrm{~mm}$ ), spectral resolution ( $49 \mathrm{kHz}$ at 3 and $2 \mathrm{~mm}$; and $195 \mathrm{kHz}$ at $1 \mathrm{~mm}$ ), and sensitivity (median noise $8.1 \mathrm{mK}, 18.5 \mathrm{mK}$ and $8.6 \mathrm{mK}$ at 3,2 ans $1 \mathrm{~mm}$ respectively). A detailed presentation of the observing strategy and data reduction process will be given in a forthcoming paper. In short, all frequencies were observed with two different frequency tunings and the Horsehead PDR and dense core positions were alternatively observed every 15 minutes in positionswitching mode with a common fixed off-position. This observing strategy allows us to remove potential ghost lines that are incompletely rejected from a strong line in the image sideband (the typical rejection of the EMIR sideband-separating mixers is only $13 \mathrm{~dB}$ ).

The line density at $3 \mathrm{~mm}$ is, on average, 5 and 4 lines/GHz in the PDR and dense core, respectively. At 2 and $1 \mathrm{~mm}$, the line density is 1 line/GHz in both the PDR and dense core. The contribution of molecular lines to the total flux at $1.2 \mathrm{~mm}$ is estimated to be $14 \%$ at the PDR and $16 \%$ at the dense core. Approximately 30 species (plus their isotopologues) are detected with up to 7 atoms in the PDR and the dense core.

\subsection{IRAM-30m and PdBI maps}

Figure 1 displays the integrated emission of the $\mathrm{C}_{2} \mathrm{H}, \mathrm{CH}_{3} \mathrm{CHO}, \mathrm{HCO}, \mathrm{CF}^{+}, \mathrm{DCO}^{+}, \mathrm{p}-\mathrm{H}_{2} \mathrm{CO}$, and $\mathrm{CH}_{3} \mathrm{OH}-\mathrm{A}$ lines as well as the $1.2 \mathrm{~mm}$ continuum emission. The observation parameters are summarized in Table 1 A reference is given where a detailed description of the observations and data reduction can be found for each map.

The A- and E-type $\mathrm{CH}_{3} \mathrm{CHO} 5_{15}-4_{14}$ lines at $93.581 \mathrm{GHz}$ and $93.595 \mathrm{GHz}$ were observed simultaneously with the A- and E-type $\mathrm{CH}_{3} \mathrm{CHO} 6_{16}-5_{15}$ lines at $112.249 \mathrm{GHz}$ and $112.254 \mathrm{GHz}$ during $\sim 17$ hours of average summer weather in August and September 2013. We used the two polarizations of the EMIR receivers and the FTS backends at $49 \mathrm{kHz}$ spectral resolution. We used the position-switching, on-the-fly observing mode. The off-position offsets were $(\delta \mathrm{RA}, \delta \mathrm{Dec})=\left(100^{\prime \prime}, 0^{\prime \prime}\right)$, that is, the $\mathrm{H}$ II region ionized by $\sigma$ Ori and free of molecular emission. We observed along and perpendicular to the direction of the exciting star in zigzags (i.e., \pm the lambda and beta scanning direction). From our knowledge of the IRAM-30m telescope, we estimate the absolute position accuracy to be $3^{\prime \prime}$.

The IRAM-30m data were processed with the GILDAS/CLASS software. The data were first calibrated to the $T_{\mathrm{A}}^{*}$ scale using the chopper-wheel method ${ }^{43}$. The data were converted to main-beam temperatures $\left(T_{\mathrm{mb}}\right)$ using the forward and main-beam efficiencies $\left(F_{\text {eff }}\right.$ and $\left.B_{\text {eff }}\right)$. The resulting amplitude accuracy is $10 \%$. We then computed the experimental noise by subtracting a zeroth-order baseline from every spectra. A systematic comparison of this noise value with the theoretical noise computed from the system temperature, the integration time, and the channel width allowed us to filter out outlier spectra. The spectra where then gridded to a data cube through a convolution with a Gaussian kernel. In order to increase the signal-to-noise ratio, we smoothed the four A- and E-type $\mathrm{CH}_{3} \mathrm{CHO}$ lines to the largest angular resolution and then averaged all the data. The averaged map, which has a final resolution of $30^{\prime \prime}$, is shown in Fig 1

\section{Recent results from the Horsehead WHISPER line survey}

\section{1 $\mathrm{CF}^{+}$: a tracer of $\mathrm{C}^{+}$and a measure of the fluorine abundance}

$\mathrm{CF}^{+}$, which was only detected in the Orion Bar before ${ }^{44}$, was detected toward the illuminated edge of the Horsehead nebula by Guzmán et al. ${ }^{22}$. The $\mathrm{CF}^{+}$ion, which is formed by reactions of $\mathrm{HF}$ and $\mathrm{C}^{+}$, is expected to be the second most important fluorine reservoir, after $\mathrm{HF}$, in regions where $\mathrm{C}^{+}$is abundant ${ }^{45}$. Indeed, the $\mathrm{CF}^{+}$emission is concentrated toward the edge of the Horsehead, delineating the western edge of the $\mathrm{DCO}^{+}$emission (see Fig. 1). Theoretical models predict that there is a significant overlap between $\mathrm{CF}^{+}$and $\mathrm{C}^{+}$at the edges of molecular clouds. Therefore, we propose that $\mathrm{CF}^{+}$can be used as a proxy of $\mathrm{C}^{+}$, but that can be observed from ground-based telescopes, unlike $\mathrm{C}^{+}$for which we need to go to space. This can be a powerful tool, because the [C II] $157.8 \mu \mathrm{m}$ line is 
the main cooling mechanism of the diffuse gas, and the cooling of the medium, which allows the gas to compress, is a crucial step in the formation of new stars. Moreover, given the simple chemistry of fluorine and assuming that the $\mathrm{CF}^{+}$destruction is dominated by dissociative recombination with electrons with little contribution from photodissociation (which is true only in low-UV PDRs), one obtains that the $\mathrm{CF}^{+}$column density is proportional to the column density of HF. Then, assuming that in molecular clouds all fluorine is in its molecular form, the elemental abundance of fluorine can be derived directly from $\mathrm{CF}^{+}$observations. We infer $\mathrm{F} / \mathrm{H}=(0.6-1.5) \times 10^{-8}$ in good agreement with the one found in diffuse molecular clouds 46 , and somewhat lower than the solar value 47 and the one found in the diffuse atomic gas $\underline{48}$. Finally, because the Horsehead shows narrow emission lines, in contrast to other PDRs like the Orion Bar, Guzmán et al. ${ }^{49}$ were able to resolve the two hyperfine components in the $\mathrm{CF}^{+} J=1-0$ line and to compare with ab initio computations of the $\mathrm{CF}^{+}$spin rotation constant. The derived theoretical value of $C_{I}=229.2 \mathrm{kHz}$ agrees well with the observations. The Horsehead is thus a good laboratory for precise spectroscopic studies of species present in far-UV illuminated environments.

\subsection{Detection of a new molecule in space, tentatively attributed to $1-\mathrm{C}_{3} \mathrm{H}^{+}$}

Thanks to the sensitive observations and large bandwidth covered by the Horsehead WHISPER line survey, a consistent set of 8 lines were detected toward the PDR position, that could not be associated to any transition listed in the public line catalogs. The observed lines can be well fitted with a linear rotor model, implying a closed-shell molecule. The deduced rotational constant value is close to that of $\mathrm{C}_{3} \mathrm{H}$. In addition, the spatial distribution of the species integrated emission has a shape similar to radical species such as $\mathrm{HCO}$, and small hydrocarbons such as $\mathrm{C}_{2} \mathrm{H}$ (see Fig. 1). Therefore, Pety et al. $\frac{35}{3}$ attributed the detected lines to the small hydrocarbon cation $1-\mathrm{C}_{3} \mathrm{H}^{+}$.

In the family of small hydrocarbons, Pety et al. ${ }^{20}$ found that $\mathrm{C}_{3} \mathrm{H}$ and $\mathrm{C}_{3} \mathrm{H}_{2}$ are about 1 order of magnitude more abundant in PDRs than current pure gas-phase models predict. An additional formation mechanism is therefore needed. One possibility to explain the observed high abundance of hydrocarbons in PDRs is the so called Top-Down model. In this scenario polycyclic aromatic hydrocarbons (PAHs) are fragmented into small hydrocarbons in PDRs due to the strong UV fields ${ }^{20,31,50}$. In the same way, PAHs are formed by photo-evaporation of very small grains 51,52 . The discovery of $\mathrm{C}_{3} \mathrm{H}^{+}$, which is an intermediate species in the gas-phase formation scenario, brings further constraints to the formation pathways of the small hydrocarbons. Indeed, we find a $1-\mathrm{C}_{3} \mathrm{H}^{+}$abundance which is too low to explain the observed abundance of the other related small hydrocarbons by means of pure gas-phase chemical reactions.

The lines detected in the Horsehead have been detected in other environments, like the Orion Bar (Cuadrado et al. in prep) and $\mathrm{Sgr} \mathrm{B} 2 \frac{53}{3}$, which confirms the presence of the carrier in the ISM. But the attribution of the unidentified lines to $1-\mathrm{C}_{3} \mathrm{H}^{+}$has been questioned by Huang et al. $\stackrel{54}{ }$, because their theoretical calculations of the spectroscopic constants of $\mathrm{C}_{3} \mathrm{H}^{+}$differ from the ones inferred from our observations. Fortenberry et al. $\frac{55}{2}$ proposed that a more plausible candidate is the hydrocarbon anion $\mathrm{C}_{3} \mathrm{H}^{-}$. However, if the unknown species is the anion, it would be the first anion detected in the Horsehead, and the ratio of $\mathrm{C}_{3} \mathrm{H}^{-}$to neutral $\mathrm{C}_{3} \mathrm{H}$ would be $\sim 57 \%$, which is higher than any anion to neutral ratio detected in the ISM so far. In addition, the lines were not detected in the dark cloud TMC 1, where other anions have been already detected. Moreover, because $\mathrm{C}_{3} \mathrm{H}^{-}$is an asymmetric rotor, the lines detected in the Horsehead would correspond to the $K_{a}=0$ ladder and the lines from the $K_{a}=1$ ladder should also be detected. We find no evidence of the $K_{a}=1$ lines of $\mathrm{C}_{3} \mathrm{H}$ in the observations of the Horsehead $\mathrm{PDR}^{56}$. For all these reasons it would be unexpected that the carrier of the unidentified lines is the anion, $\mathrm{C}_{3} \mathrm{H}^{-}$. The observations favor the assignment of the unidentified species to the hydrocarbon cation, $\mathrm{C}_{3} \mathrm{H}^{+}$, as the most likely candidate. However, A direct measurement in the laboratory is necessary to provide a definitive answer and close the controversy created by these observations in the Horsehead. Ongoing high-angular PdBI observations of this species in the Horsehead PDR will allow us to better constrain the chemistry of small hydrocarbons in the near future.

\subsection{Photo-desorption of dust grain ice mantles: $\mathrm{H}_{2} \mathrm{CO}$ and $\mathrm{CH}_{3} \mathrm{OH}$}

Relatively simple organic molecules, like $\mathrm{H}_{2} \mathrm{CO}$ and $\mathrm{CH}_{3} \mathrm{OH}$, are key species in the synthesis of more complex molecules in the ISM ${ }^{57-59}$, that could eventually end up in proto-planetary disks, and hence in new planetary systems. They are also used to probe the temperature and density of the gas in different astrophysical sources $60-62$. Both $\mathrm{H}_{2} \mathrm{CO}$ and $\mathrm{CH}_{3} \mathrm{OH}$ have been detected in a wide range of interstellar environments such as dark clouds, proto-stellar cores and comets, with high abundances $\left(10^{-6}-10^{-9}\right)$ with respect to total hydrogen. Unlike $\mathrm{H}_{2} \mathrm{CO}$, which can be formed efficiently in both the gas-phase and on the surfaces of dust grains, $\mathrm{CH}_{3} \mathrm{OH}$ is thought to be formed mostly on the ices, through the successive additions of hydrogen atoms to adsorbed $\mathrm{CO}$ molecules.

Guzmán et al. ${ }^{36}$ and Guzman et al. 24 observed several millimeter lines of $\mathrm{H}_{2} \mathrm{CO}$ and $\mathrm{CH}_{3} \mathrm{OH}$ toward the PDR and dense core positions in the Horsehead. The inferred abundances from the observations (see Table 2) were compared to PDR models that include either pure gas-phase chemistry or both gas-phase and grain surface 


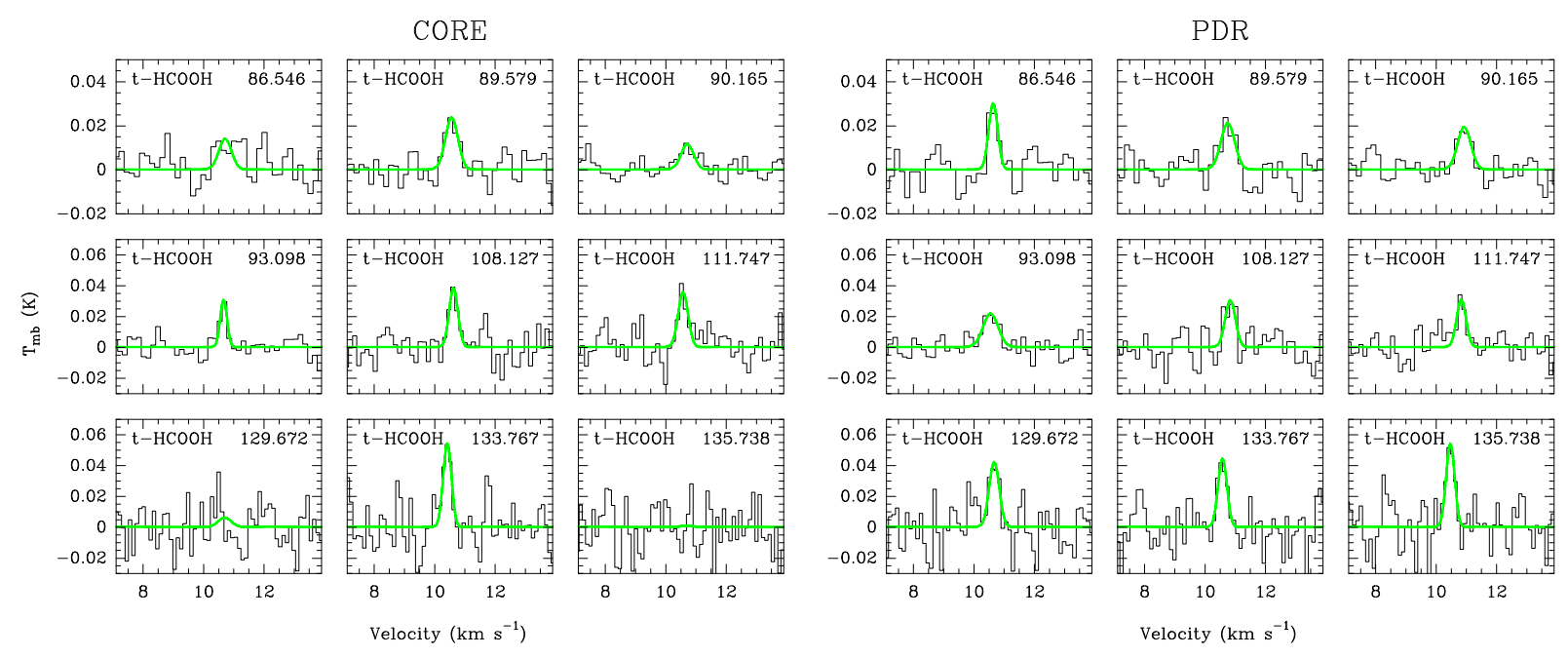

Fig. 2 HCOOH lines detected toward the dense core (left) and PDR (right). For each line, the same scale is used at both positions to ease the comparison.
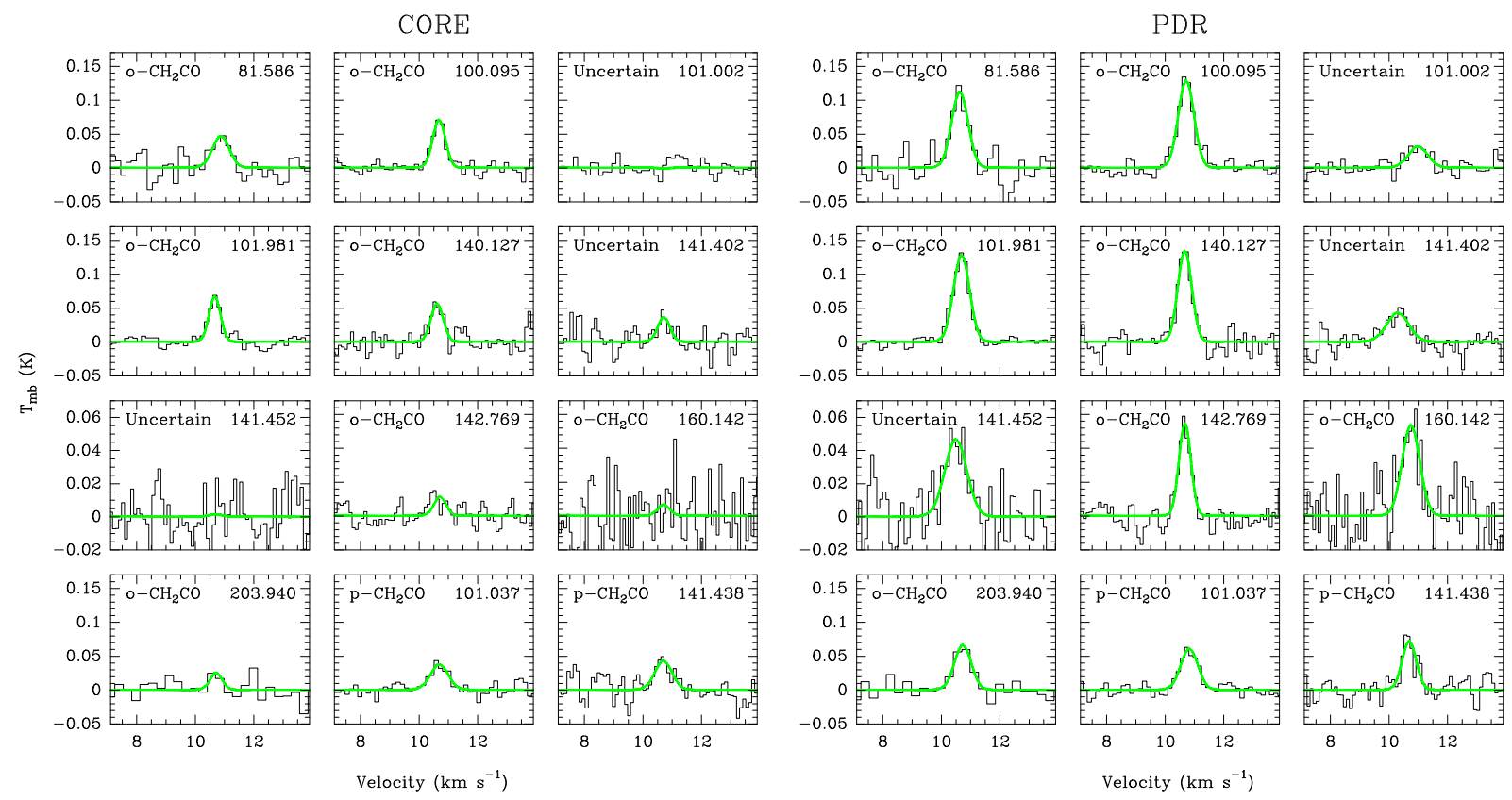

Fig. $3 \mathrm{CH}_{2} \mathrm{CO}$ lines detected toward the dense core (left) and PDR (right). For each line, the same scale is used at both positions to ease the comparison.

chemistry. Pure gas-phase models cannot reproduce the observed abundances of either $\mathrm{H}_{2} \mathrm{CO}$ or $\mathrm{CH}_{3} \mathrm{OH}$ at the PDR position. Both species are therefore mostly formed on the surface of dust grains, probably through the successive hydrogenation of $\mathrm{CO}$ ices and are subsequently released into the gas-phase through photodesorption. At the dense core, on the other hand, photodesorption of ices is needed to explain the observed abundance of $\mathrm{CH}_{3} \mathrm{OH}$, while a pure gas-phase model can reproduce the observed $\mathrm{H}_{2} \mathrm{CO}$ abundance. The different formation routes for $\mathrm{H}_{2} \mathrm{CO}$ at the PDR and dense core suggested by the models is strengthened by the different ortho-to-para ratios derived from the observations ( $\sim 3$ at the dense core, $\sim 2$ at the PDR).

In addition to the lines detected in the WHISPER survey, we obtained high-angular resolution $\left(6^{\prime \prime}\right)$ maps of $\mathrm{H}_{2} \mathrm{CO}$ and $\mathrm{CH}_{3} \mathrm{OH}$ with the IRAM-PdBI. Fig. 11 shows the $\mathrm{H}_{2} \mathrm{CO}$ and $\mathrm{CH}_{3} \mathrm{OH}$ single-dish $30 \mathrm{~m}$ maps that were used for the short-spacing of the PdBI observations. The $\mathrm{H}_{2} \mathrm{CO}$ emission map presents a peak at the dense core position, while $\mathrm{CH}_{3} \mathrm{OH}$ presents a dip in its emission at the same position. The observations thus suggest that $\mathrm{CH}_{3} \mathrm{OH}$ is depleted in the dense core. This way, gas-phase $\mathrm{CH}_{3} \mathrm{OH}$ is present in an envelope around the dense core, while $\mathrm{H}_{2} \mathrm{CO}$ is present in both the envelope and the dense core itself. Indeed, we expect photodesorption to be more efficient at the PDR than at the far-UV shielded dense core. We thus conclude that photo-desorption of ices is an efficient mechanism to release species into the gas-phase in far-UV illuminated regions. 
CORE

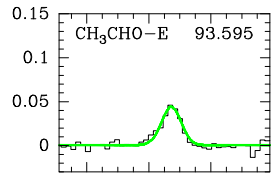

0.1 CH

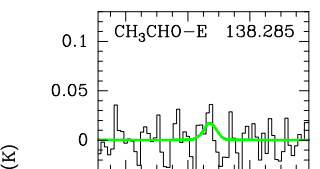

:
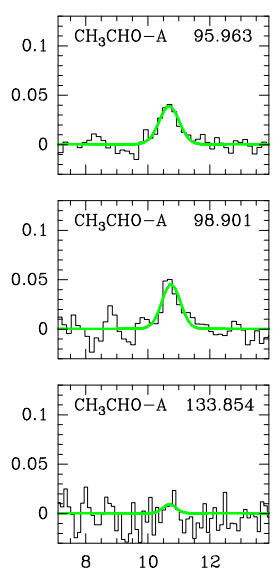
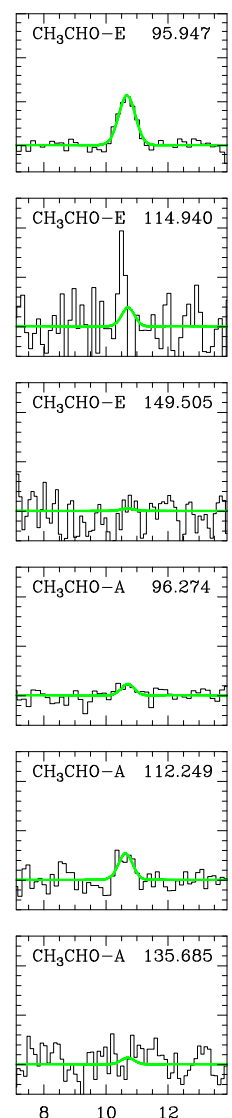

Velocity $\left(\mathrm{km} \mathrm{s}^{-1}\right)$
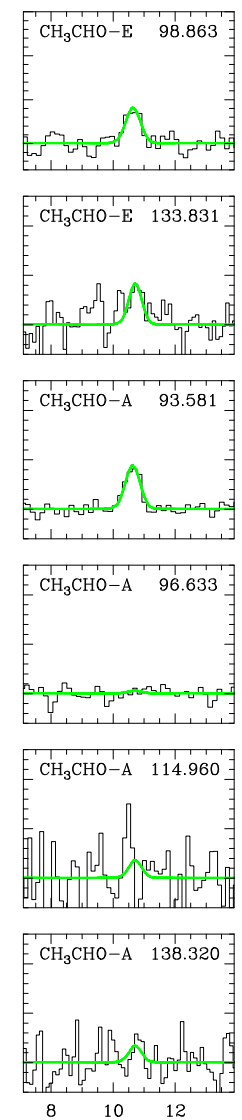

PDR
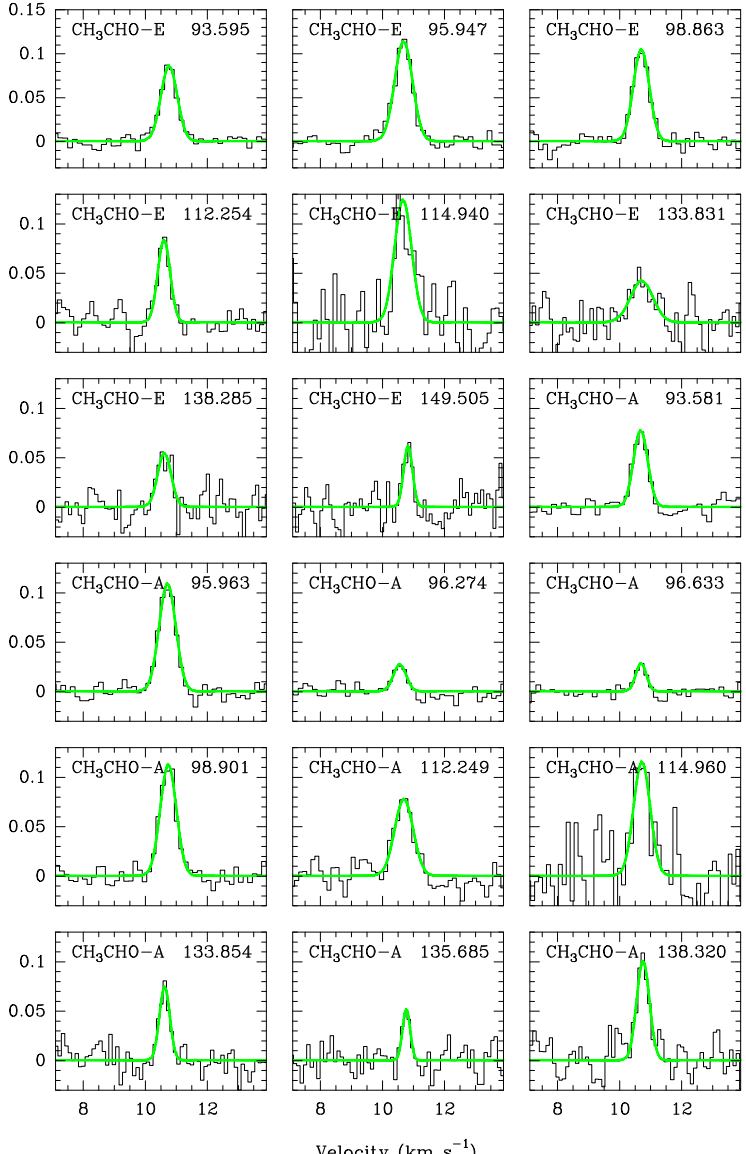

Fig. $4 \mathrm{CH}_{3} \mathrm{CHO}$ lines detected toward the dense core (left) and PDR (right). For each line, the same scale is used at both positions to ease the comparison.

$\mathrm{CORE}$
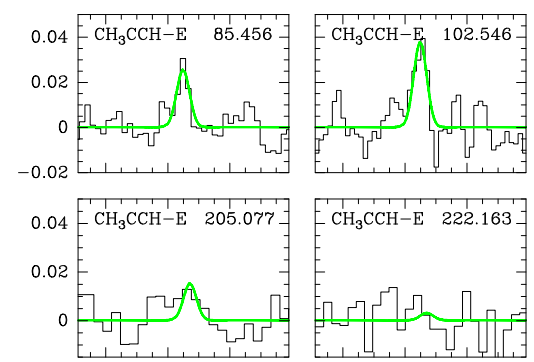

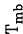
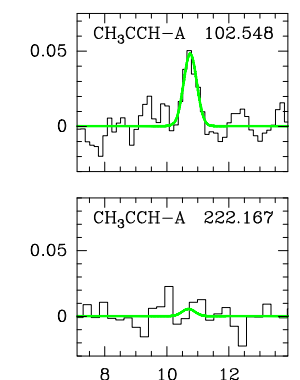
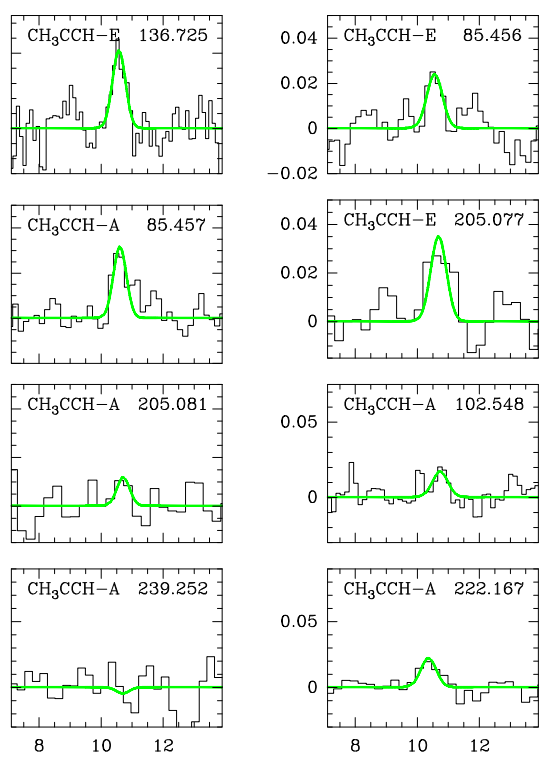

Velocity $\left(\mathrm{km} \mathrm{s}^{-1}\right)$

PDR
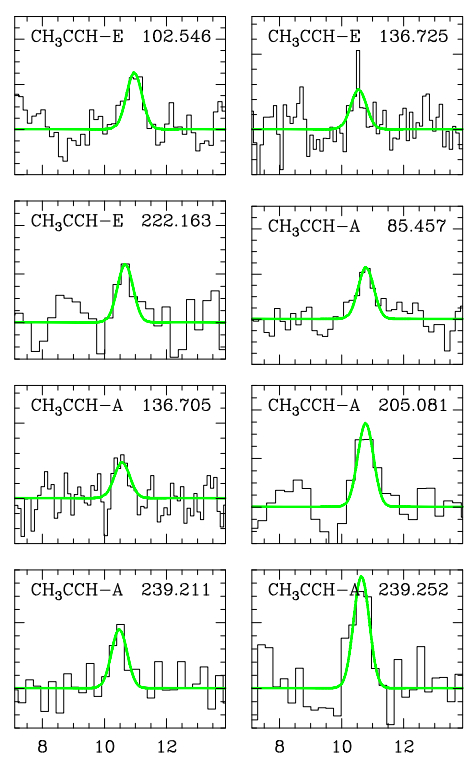

Velocity $\left(\mathrm{km} \mathrm{s}^{-1}\right)$

Fig. $5 \mathrm{CH}_{3} \mathrm{CCH}$ lines detected toward the dense core (left) and PDR (right). For each line, the same scale is used at both positions to ease the comparison. 


\subsection{Nitrile molecules: $\mathrm{CH}_{3} \mathrm{CN}, \mathrm{CH}_{3} \mathrm{NC}$ and $\mathrm{HC}_{3} \mathrm{~N}$}

Moderately complex nitriles like $\mathrm{CH}_{3} \mathrm{CN}$ and $\mathrm{HC}_{3} \mathrm{~N}$ are easily detected in (massive) star forming regions. In particular, the $\mathrm{CH}_{3} \mathrm{CN}$ emission has been found to be enhanced in star forming regions containing an ultracompact $\mathrm{H}$ II region $\underline{63}$. $\mathrm{CH}_{3} \mathrm{CN}$ is thought to be a good tracer of the physical conditions in warm and dense regions. Gratier et al. $\frac{37}{\underline{7}}$ detected several lines of $\mathrm{CH}_{3} \mathrm{CN}$ and $\mathrm{HC}_{3} \mathrm{~N}$ in the PDR and dense core. $\mathrm{CH}_{3} \mathrm{NC}$ and $\mathrm{C}_{3} \mathrm{~N}$ are also detected toward the PDR. The observations show that the chemistry of $\mathrm{HC}_{3} \mathrm{~N}$ and $\mathrm{CH}_{3} \mathrm{CN}$ is quite different. Indeed, we find that $\mathrm{CH}_{3} \mathrm{CN}$ is 30 times more abundant in the far-UV illuminated gas than in the far-UV shielded core, while $\mathrm{HC}_{3} \mathrm{~N}$ has a similar abundance in both positions. The high abundance of $\mathrm{CH}_{3} \mathrm{CN}$ inferred in the PDR is surprising because the photodissociation of this complex molecule is expected to be efficient in far-UV illuminated regions. The observed abundance in the PDR cannot be reproduced by current pure gas-phase chemical models. We have shown that photodesorption is an efficient mechanism to release $\mathrm{H}_{2} \mathrm{CO}$ and $\mathrm{CH}_{3} \mathrm{OH}$ in the PDR, but the case of $\mathrm{CH}_{3} \mathrm{CN}$ is even more extreme as it is 30 times more abundant there than in the dense core, while $\mathrm{H}_{2} \mathrm{CO}$ presents similar abundances in both positions. This shows that there is something specific in the chemistry of $\mathrm{CH}_{3} \mathrm{CN}$ in FUV-illuminated regions. $\mathrm{CH}_{3} \mathrm{CN}$ could be produced on the ices by the photo-processing of $\mathrm{N}$ bearing species followed by photodesorption, but it could also be produced in the gas-phase if the abundances of its gas-phase precursors, $\mathrm{HCN}$ and $\mathrm{CH}_{3}^{+}$, are enhanced. The detection of $\mathrm{CH}_{3} \mathrm{NC}$ at the PDR, which results in an $\mathrm{CH}_{3} \mathrm{NC} / \mathrm{CH}_{3} \mathrm{CN}$ isomeric ratio of 0.15 , suggests that $\mathrm{CH}_{3} \mathrm{NC}$ could also form on the surfaces of dust grains through far-UV irradiation of $\mathrm{CH}_{3} \mathrm{CN}$ ices leading to isomerization.

\section{Other complex molecules in PDRs}

Within the WHISPER line survey, several lines of $\mathrm{HCOOH}, \mathrm{CH}_{2} \mathrm{CO}, \mathrm{CH}_{3} \mathrm{CHO}$ and $\mathrm{CH}_{3} \mathrm{CCH}$ are detected. These are presented in Figs. 2] to 3. The spectroscopic parameters and Gaussian fit results of the detected lines are listed in Appendix $\AA$ The spectroscopic parameters are taken from the CDMS $\underline{64}$ and JPL $\underline{65}$ data bases. Several lines of ketene and acetaldehyde are clearly detected $(S / N>5 \sigma)$. The formic acid and propyne present several but fainter $(2 \sigma-5 \sigma)$ lines toward the PDR and dense core positions. In order to confirm the correct identification of these molecules, we have modeled the spectrum of each species assuming LTE and optically thin emission, and checked that there are no predicted lines missing in the line survey. Both ortho and para forms of $\mathrm{CH}_{2} \mathrm{CO}$ are detected, as well as both $\mathrm{E}$ and $\mathrm{A}$ forms of $\mathrm{CH}_{3} \mathrm{CHO}$ and $\mathrm{CH}_{3} \mathrm{CCH}$. All the lines detected of the formic acid correspond to the trans isomer. $\mathrm{CH}_{2} \mathrm{CO}, \mathrm{CH}_{3} \mathrm{CHO}$ lines are brighter toward the PDR position than toward the dense core, while $\mathrm{HCOOH}$ and $\mathrm{CH}_{3} \mathrm{CCH}$ lines have similar brightness in both positions.

The beam-averaged column density of each molecule was estimated using rotational diagrams because no collisional coefficients are available. The detected lines cover a sufficiently large energy range to derive a rotational temperature. The resulting rotational diagrams are shown in Fig. 6. The inferred abundances with respect to $\mathrm{H}$ nuclei are summarized in Table 2 The partition function was computed independently for ortho and para nuclear spin forms (for ketene), and for $\mathrm{E}$ and $\mathrm{A}$ symmetry forms (for $\mathrm{CH}_{3} \mathrm{CHO}$ ), by direct summation over the energy levels.

\section{Formic acid}

The data in the rotational diagram of $\mathrm{HCOOH}$ present a large scatter because all the detected lines are weak and therefore have a larger uncertainty than the lines of the other complex molecules. The rotational temperature is poorly constrained. The inferred abundances of $\sim 5 \times 10^{-11}$ (PDR) and $\sim 1 \times 10^{-11}$ (core) are thus also uncertain and should be considered as an order of magnitude estimate. Deeper integration times are needed to better constrain the $\mathrm{HCOOH}$ abundance.

\section{Ketene}

The ortho and para symmetries of $\mathrm{CH}_{2} \mathrm{CO}$ were treated as different species. When including all the $\mathrm{o}-\mathrm{CH}_{2} \mathrm{CO}$ and $\mathrm{p}-\mathrm{CH}_{2} \mathrm{CO}$ lines detected in the PDR, the fit results in rotational temperatures of $154 \mathrm{~K}$ and $120 \mathrm{~K}$ for $\mathrm{o}-\mathrm{CH}_{2} \mathrm{CO}$ and $\mathrm{p}-\mathrm{CH}_{2} \mathrm{CO}$, respectively. These temperatures are much larger than the kinetic temperature at the PDR ( $\sim 60 \mathrm{~K})$. When the three lines of $\mathrm{CH}_{2} \mathrm{CO}$ with energies above $80 \mathrm{~K}$ that are detected at the PDR (gray points in Fig. 6) are not considered in the rotational diagrams, the derived rotational temperatures decrease to $18 \mathrm{~K}$ for both ortho and para species. This temperature agrees much better with the expected sub-thermal excitation in the Horsehead, and also with the derived rotational temperatures at the dense core. The enhanced emission of the three lines with $E_{u}>80 \mathrm{~K}$ could be the result of an excitation effect. However, these lines are broader $\left(0.8 \mathrm{~km} \mathrm{~s}^{-1}\right)$ than the other $\mathrm{CH}_{2} \mathrm{CO}$ lines and than other species detected in the Horsehead PDR (the typical linewidth is $0.6 \mathrm{~km} \mathrm{~s}^{-1}$ ). In addition, the velocity of these three lines differs by $0.2 \mathrm{~km} \mathrm{~s}^{-1}$ from the systemic velocity of $10.7 \mathrm{~km} \mathrm{~s}^{-1}$ found for most species in the Horsehead. Cummins et al. $\frac{25}{2}$ detected several o- $\mathrm{CH}_{2} \mathrm{CO}$ 
Table 3 Dipole moments of complex molecules

\begin{tabular}{lcr}
\hline Species & $\begin{array}{c}\text { Dipole moment } \\
\text { (Debye) }\end{array}$ & Reference \\
\hline $\mathrm{HCOOH}$ & 1.4 & Kim et al..$\underline{66}$ \\
$\mathrm{CH}_{2} \mathrm{CO}$ & 1.45 & Hannay and Smyth $\frac{67}{68}$ \\
$\mathrm{CH}_{3} \mathrm{CHO}$ & 2.7 & Kleiner et al. $\frac{68}{69}$ \\
$\mathrm{CH}_{3} \mathrm{CCH}$ & 0.78 & Burrell et al. $\underline{\underline{60}}$ \\
\hline
\end{tabular}

lines toward Sgr B2, including the $5_{33}-4_{32}$ at $101.002 \mathrm{GHz}$, which is one of the three lines detected in the Horsehead with $E_{u}>80 \mathrm{~K}$. They also obtained a large rotational temperature, which led them to remove this line from the fit and consider the identification as uncertain. At the dense core position in the Horsehead, the derived rotational temperature for $\mathrm{o}-\mathrm{CH}_{2} \mathrm{CO}$ is $\sim 14 \mathrm{~K}$. Only two lines of $\mathrm{p}-\mathrm{CH}_{2} \mathrm{CO}$ are detected at the dense core, resulting in a rotational temperature of $\sim 20 \mathrm{~K}$. Ketene is $\sim 3$ times more abundant in the PDR than in the dense core, with abundances of $1.5 \times 10^{-10}(\mathrm{PDR})$ and $4.9 \times 10^{-11}$ (core). The ortho-to-para ratio is poorly constrained, resulting in $o / p=7.1 \pm 4.2(\mathrm{PDR})$ and $o / p=5.7 \pm 3.9$ (dense core).

\section{Acetaldehyde}

The $\mathrm{E}$ and $\mathrm{A}$ symmetries of $\mathrm{CH}_{3} \mathrm{CHO}$ were also treated as different species. Acetaldehyde has a large dipole moment (2.7 Debye, see Table 3) compared to methanol (1.7 Debye). Since the critical density is proportional to $\mu^{2}$, sub-thermal effects are important for $\mathrm{CH}_{3} \mathrm{CHO}^{27}$. Indeed, the derived rotational temperatures for $\mathrm{CH}_{3} \mathrm{CHO}$ $(6-10 \mathrm{~K})$ are the lowest ones of all the molecules discussed here. The derived column density of $\mathrm{CH}_{3} \mathrm{CHO}$ is $\sim 3$ times larger in the PDR than in the dense core. The inferred E/A ratio is $\sim 0.3 \pm 0.1$ (PDR) and $\sim 0.2 \pm 0.2$ (core), i.e., much lower than unity in both positions.

Figure 1 displays the averaged $\mathrm{E}$ and $\mathrm{A} \mathrm{CH}_{3} \mathrm{CHO}$ lines at $93.6 \mathrm{GHz}$. The $\mathrm{CH}_{3} \mathrm{CHO}$ emission clearly peaks at the PDR position, delineating the edge of the Horsehead nebula. The $\mathrm{CH}_{3} \mathrm{CHO}$ emission resembles the $\mathrm{HCO}$ emission at the $30 \mathrm{~m}$ telescope angular resolution of $30^{\prime \prime}$, which is concentrated in a narrow structure peaking at the PDR. Higher-angular resolution $\left(6^{\prime \prime}\right)$ observations by Gerin et al. ${ }^{21}$ showed that the HCO emission traces a filament of $\sim 12^{\prime \prime}$ width. The similarities between the emission of $\mathrm{HCO}$ and $\mathrm{CH}_{3} \mathrm{CHO}$ thus suggest that $\mathrm{CH}_{3} \mathrm{CHO}$ also arises from a narrow filament that peaks at the PDR position. Assuming a filament of $12^{\prime \prime}$ centered at the PDR, we estimate that $\sim 10 \%$ of the $\mathrm{CH}_{3} \mathrm{CHO}$ emission detected at the dense core corresponds to beam pick-up from the PDR due to the large beam at $93 \mathrm{GHz}\left(27^{\prime \prime}\right)$. The remaining emission towards the core line of sight could arise from the cloud surface, as was found for $\mathrm{CS}^{33}$ and $\mathrm{HCO} .21$

\section{Propyne}

If $\mathrm{CH}_{3} \mathrm{CCH}-\mathrm{E}$ and $\mathrm{CH}_{3} \mathrm{CCH}-\mathrm{A}$ are treated as different species, the derived rotational temperatures at the PDR are $\sim 70 \mathrm{~K}$ and $\sim 53 \mathrm{~K}$ for $\mathrm{E}$ and $\mathrm{A}$ symmetries, respectively. At the dense core, a rotational temperature of $\sim 70 \mathrm{~K}$ is inferred for the E symmetry. A rotational temperature cannot be inferred for $\mathrm{CH}_{3} \mathrm{CCH}-\mathrm{A}$ at the dense core because the two lines that are detected are faint. The two symmetries are therefore considered as the same species, resulting in a rotational temperature of $\sim 55 \mathrm{~K}$ and a total column density for the E- and A-type $\mathrm{CH}_{3} \mathrm{CCH}$ of $\sim 2 \times 10^{13} \mathrm{~cm}^{-2}$ at both the PDR and dense core position. The inferred column density at the PDR position does not change when the E and A symmetries are separated.

\section{Discussion}

Ketene and acetaldehyde are thought to form on the surface of dust grains. Indeed, $\mathrm{CH}_{3} \mathrm{CHO}$ has been proposed as a candidate for the $7.41 \mu \mathrm{m}$ absorption feature observed toward high-mass protostars. Ketene and acetaldehyde are thought to form together on the ices through $\mathrm{C}$ and $\mathrm{H}$ atom additions to $\mathrm{CO} \stackrel{30}{ }$. The expected sequence is

$$
\mathrm{CO} \stackrel{\mathrm{H}}{\rightarrow} \mathrm{HCO} \stackrel{\mathrm{C}}{\rightarrow} \mathrm{HCCO} \stackrel{\mathrm{H}}{\rightarrow} \mathrm{CH}_{2} \mathrm{CO} \stackrel{2 \mathrm{H}}{\longrightarrow} \mathrm{CH}_{3} \mathrm{CHO} .
$$

Ketene can also be formed from reactions between $\mathrm{C}_{2} \mathrm{H}_{2}$ and $\mathrm{O}$ in irradiated $\mathrm{H}_{2} \mathrm{O}$-rich and $\mathrm{CO}_{2}$-rich ices, as shown by recent laboratory experiments $\underline{70}$. Laboratory experiments also show that reactions between $\mathrm{C}_{2} \mathrm{H}_{4}$ and $\mathrm{O}$ can produce acetaldehyde and its isomer, ethylene oxide $\left(\mathrm{CH}_{2} \mathrm{OCH}_{2}\right)^{71} . \mathrm{CH}_{2} \mathrm{CO}$ and $\mathrm{CH}_{3} \mathrm{CHO}$ could also be formed in the gas-phase, through ion-molecule and neutral-neutral reactions. Indeed, gas-phase models predict abundances that are comparable to those measured in some of the high-mass protostars observed by Bisschop et al. 27 . 

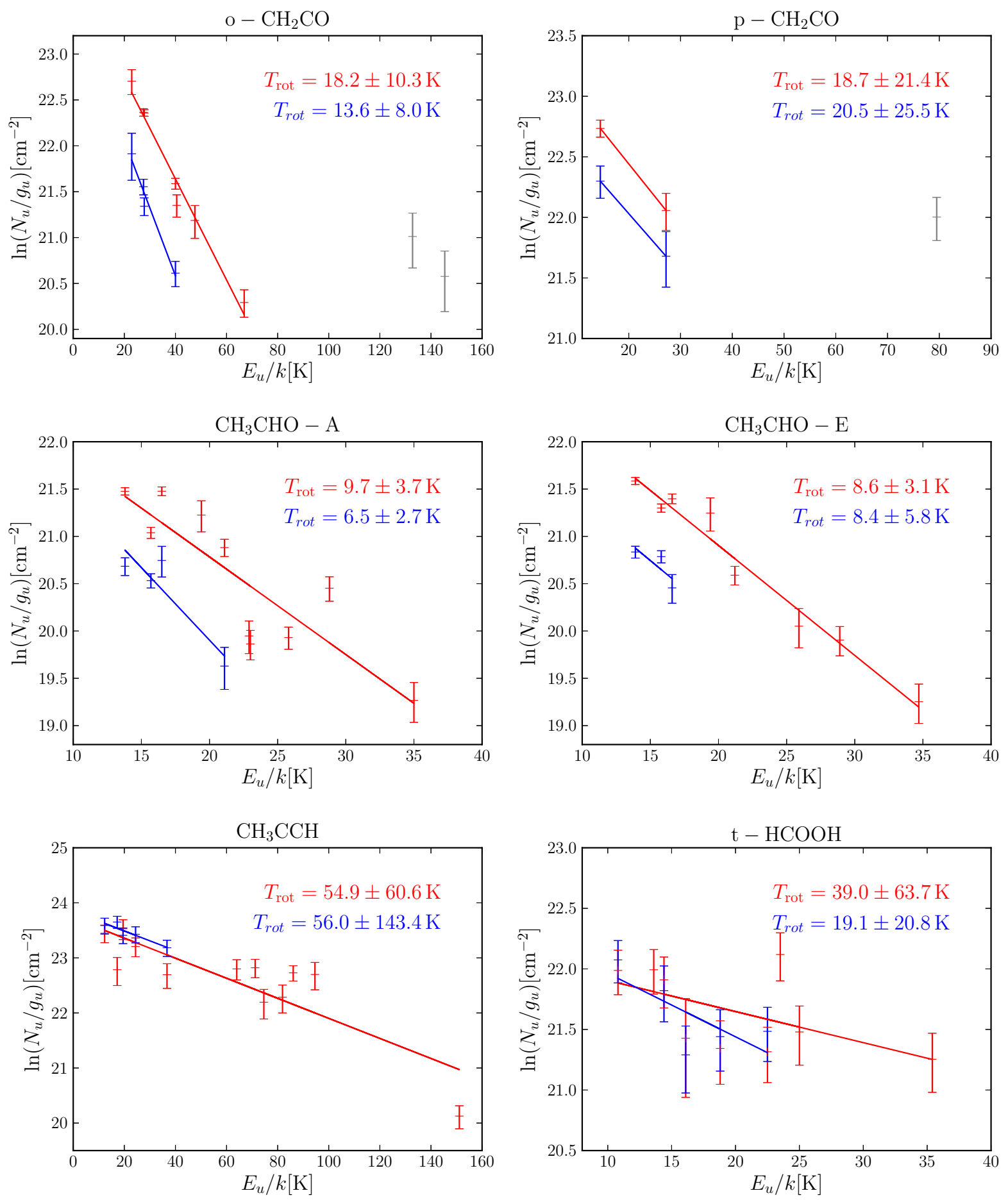

Fig. 6 Rotational diagrams for the PDR (red) and dense core (blue). The gray points correspond to the three lines detected at the PDR whose identification is uncertain. They are not considered in the fit.

The exact formation path of $\mathrm{HCOOH}$ on ices is unclear, though $\mathrm{HCOOH}$ ices have been observed in starforming regions $\underline{72}$. Several formation paths on grain surfaces have been proposed in the past. It could form from the addition of $\mathrm{H}$ and $\mathrm{O}$ atoms to $\mathrm{CO}$ or to $\mathrm{CO}_{2} \underline{\underline{73}}$. Garrod et al. $\frac{74}{\underline{4}}$ proposed that $\mathrm{HCOOH}$ could form through reactions between $\mathrm{HCO}$ and $\mathrm{OH}$. More recently, Ioppolo et al. $\underline{75}$ have studied the hydrogenation of the HO-CO complex in the laboratory and showed it is an efficient formation route to $\mathrm{HCOOH}$.

The abundances derived in the Horsehead PDR for $\mathrm{HCOOH}, \mathrm{CH}_{2} \mathrm{CO}$, and $\mathrm{CH}_{3} \mathrm{CHO}$, are $3-4$ times larger toward the PDR than toward the dense core. The case of $\mathrm{CH}_{3} \mathrm{CN}$ is even more extreme as it is $\sim 30$ times more abundant in the PDR than in the dense core $\frac{37}{}$. $\mathrm{CH}_{3} \mathrm{CCH}$ is only 1.5 times more abundant in the PDR than in the dense core. In contrast, methanol is $\sim 2$ times less abundant in the PDR than in the dense core. When comparing 


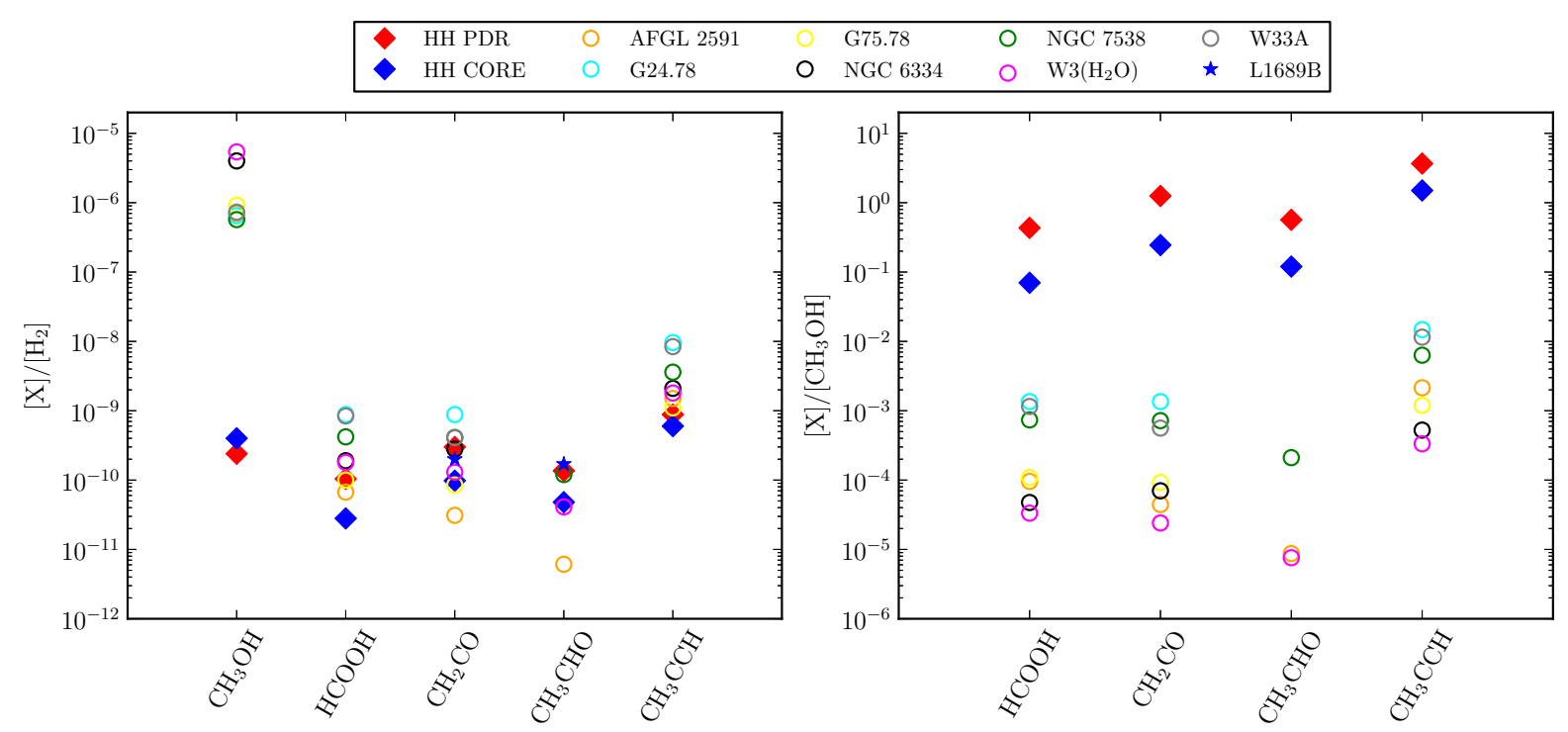

Fig. 7 Abundances with respect to $\mathrm{H}_{2}$ (left) and with respect to $\mathrm{CH}_{3} \mathrm{OH}$ (right) toward the hot core sources from Bisschop et al. 27 (open circles), the cold prestellar core from Bacmann et al. ${ }^{39}$ (blue star) and the Horsehead PDR and dense core (red and blue diamonds).

the abundances of the different molecules, we found that $\mathrm{CH}_{3} \mathrm{CCH}$ is one order of magnitude more abundant ( 3 $\left.4 \times 10^{-10}\right)$ than $\mathrm{CH}_{2} \mathrm{CO}$ and $\mathrm{CH}_{3} \mathrm{CHO}\left(2-7 \times 10^{-11}\right)$. Contrary to the other complex molecules, which present $[\mathrm{X}] /\left[\mathrm{CH}_{3} \mathrm{OH}\right]$ ratios lower than $1, \mathrm{CH}_{3} \mathrm{CCH}$ is $\sim 4$ times more abundant than methanol in the PDR, and $\sim 1.3$ times more abundant than methanol in the dense core. Öberg et al. $\stackrel{38}{2}$ also found large $\mathrm{CH}_{3} \mathrm{CCH}$ abundances $(\sim 1$ relative to methanol) toward the high-mass protostar NGC 7538 IRS9. They found the $\mathrm{CH}_{3} \mathrm{CCH} / \mathrm{CH}_{3} \mathrm{OH}$ abundance ratio to be significantly different to what models including grain surface processes predict, which suggests that an important cold formation pathway is missing for $\mathrm{CH}_{3} \mathrm{CCH}$.

Fig. 7 shows a comparison between the abundances derived in the Horsehead and those derived toward the hot corino sources from Bisschop et al. $\underline{27}$ and toward the prestellar core $\mathrm{L} 1689 \mathrm{~B} \frac{39}{3} . \mathrm{CH}_{3} \mathrm{OH}$ is several orders of magnitude more abundant toward the hot core sources than in the Horsehead. The abundances of the other complex molecules with respect to $\mathrm{H}_{2}$ vary over $\sim 1$ order of magnitude between the different hot core sources, and are comparable to the abundances derived in the Horsehead. The abundances with respect to $\mathrm{CH}_{3} \mathrm{OH}$ are also shown in the right panel of Fig. 7. In this case, the abundances of complex molecules are $\sim 3$ orders of magnitude larger in the Horsehead than in the hot cores. However, this could be a consequence of methanol and the other complex molecules tracing different regions in the hot core sources. Methanol probably traces the hot $\left(T_{\text {kin }}>100 \mathrm{~K}\right)$ gas where species have evaporated from the grains, while the other complex molecules trace the colder envelope around the protostars, where the ices have not completely evaporated but can be photodesorbed.

The fact that we only detect cold molecules $\left(\mathrm{HCOOH}, \mathrm{CH}_{2} \mathrm{CO}, \mathrm{CH}_{3} \mathrm{CHO}\right.$ and $\left.\mathrm{CH}_{3} \mathrm{CCH}\right)$ and none of the hot molecules (e.g., $\mathrm{CH}_{3} \mathrm{OCH}_{3}$ and $\mathrm{HCOOCH}_{3}$ ), is in agreement with the idea that the cold molecules are zeroth or first generation species formed on the cold grain surfaces and trace the warm/cold envelope around protostars, because their formation probably requires little energy. In the Horsehead, the enhanced abundances toward the PDR compared to the dense core (for $\mathrm{HCOOH}, \mathrm{CH}_{2} \mathrm{CO}$, and $\mathrm{CH}_{3} \mathrm{CHO}$ ), suggests that their formation is more efficient in the presence of far-UV photons. The similarities between the $\mathrm{HCO}$ and $\mathrm{CH}_{3} \mathrm{CHO}$ emission maps also suggests that the $\mathrm{CH}_{3} \mathrm{CHO}$ abundance at the PDR could be even higher than estimated here, if the emission arises from a narrow filament like HCO. This could be the result of an efficient photodesorption in the PDR, due to the larger radiation field compared to the dense core, which is consistent with the much lower than unity E/A ratio (statistical value) we infer from the observations. But it could also indicate that the formation on the grains itself is more efficient in the PDR, due to a better mobility of the molecules in ice mantles. Indeed, recent laboratories experiments have shown that the diffusion of molecules is active at $T_{\text {dust }} \gtrsim 30 \mathrm{~K}$, allowing reactions to proceed faster when the ices are warmed by far-UV photons $\frac{76.77}{}$. Dust temperatures in the Horsehead PDR range from $T_{\text {dust }} \sim 30 \mathrm{~K}$ in the PDR to $T_{\text {dust }} \sim 20 \mathrm{~K}$ in the dense core $\underline{78}$. 


\section{Conclusions}

We have carried-out an unbiased spectral line survey at 3,2 and 1mm with the IRAM-30m telescope in the Horsehead nebula, with an unprecedented combination of bandwidth, high spectral resolution and sensitivity. Two positions were observed: the warm photodissociation region (PDR) and a cold condensation shielded from the UV field, located less than $40^{\prime \prime}$ away from the PDR edge. The results of this survey include 1) the detection of $\mathrm{CF}^{+}$, which can be used as a new diagnostic of UV illuminated gas and a potential proxy of the $\mathrm{C}^{+}$emission associated to molecular gas; 2) the detection of a new species in the ISM, the small hydrocarbon $\mathrm{C}_{3} \mathrm{H}^{+}$, which confirms the topdown scenario of formation of the small hydrocarbons from PAHs and photo-erosion; 3) the detection of $\mathrm{H}_{2} \mathrm{CO}$, $\mathrm{CH}_{3} \mathrm{OH}$ and $\mathrm{CH}_{3} \mathrm{CN}$, which reveals that photo-desorption of ices is an efficient mechanism to release molecules into the gas phase; 4) and the first detection of the complex organic molecules, $\mathrm{HCOOH}, \mathrm{CH}_{2} \mathrm{CO}, \mathrm{CH}_{3} \mathrm{CHO}$ and $\mathrm{CH}_{3} \mathrm{CCH}$ in a PDR, which reveals the degree of chemical complexity reached in the UV illuminated neutral gas. Complex molecules are usually considered as hot-core tracers. The detection of these molecules in PDRs shows that they can survive in the presence of far-UV radiation, and their formation could even be enhanced due to the radiation. This opens the possibility of detecting complex molecules in other far-UV illuminated regions, such as protoplanetary disks, in the future. From this work we conclude that grain surface chemistry and non-thermal desorption are crucial processes in the ISM and therefore must be incorporated into photochemical models to interpret the observations.

\section{Acknowledgements}

V.G. thanks support from the Chilean Government through the Becas Chile scholarship program. This work was also funded by grant ANR-09- BLAN-0231-01 from the French Agence Nationale de la Recherche as part of the SCHISM project. J.R.G. thanks the Spanish MICINN for funding support through grants AYA2009-07304 and CSD2009-00038. J.R.G. is supported by a Ramón y Cajal research contract from the Spanish MICINN and co-financed by the European Social Fund.

\section{References}

1 E. L. Gibb, D. C. B. Whittet, W. A. Schutte, A. C. A. Boogert, J. E. Chiar, P. Ehrenfreund, P. A. Gerakines, J. V. Keane, A. G. G. M. Tielens, E. F. van Dishoeck and O. Kerkhof, ApJ, 2000, 536, 347-356.

2 E. L. Gibb, D. C. B. Whittet, A. C. A. Boogert and A. G. G. M. Tielens, ApJS, 2004, 151, 35-73.

3 A. C. A. Boogert, K. M. Pontoppidan, C. Knez, F. Lahuis, J. Kessler-Silacci, E. F. van Dishoeck, G. A. Blake, J.-C. Augereau, S. E. Bisschop, S. Bottinelli, T. Y. Brooke, J. Brown, A. Crapsi, N. J. Evans, II, H. J. Fraser, V. Geers, T. L. Huard, J. K. Jørgensen, K. I. Öberg, L. E. Allen, P. M. Harvey, D. W. Koerner, L. G. Mundy, D. L. Padgett, A. I. Sargent and K. R. Stapelfeldt, ApJ, $2008,678,985-1004$.

4 K. M. Pontoppidan, A. C. A. Boogert, H. J. Fraser, E. F. van Dishoeck, G. A. Blake, F. Lahuis, K. I. Öberg, N. J. Evans, II and C. Salyk, ApJ, 2008, 678, 1005-1031.

5 K. I. Öberg, A. C. A. Boogert, K. M. Pontoppidan, G. A. Blake, N. J. Evans, F. Lahuis and E. F. van Dishoeck, ApJ, $2008,678,1032-1041$.

6 S. Bottinelli, A. C. A. Boogert, J. Bouwman, M. Beckwith, E. F. van Dishoeck, K. I. Öberg, K. M. Pontoppidan, H. Linnartz, G. A. Blake, N. J. Evans, II and F. Lahuis, ApJ, 2010, 718, 1100-1117.

7 A. C. A. Boogert, T. L. Huard, A. M. Cook, J. E. Chiar, C. Knez, L. Decin, G. A. Blake, A. G. G. M. Tielens and E. F. van Dishoeck, ApJ, $2011,729,92$.

8 R. T. Garrod, $A p J, 2013, \mathbf{7 6 5}, 60$.

9 J. E. Elsila, J. P. Dworkin, M. P. Bernstein, M. P. Martin and S. A. Sandford, ApJ, 2007, 660, 911-918.

10 D. P. Glavin, A. S. Burton, J. E. Elsila, J. P. Dworkin, Q.-Z. Yin and P. Jenniskens, Lunar and Planetary Institute Science Conference Abstracts, 2013, p. 1189.

11 J. E. Elsila, D. P. Glavin and J. P. Dworkin, Meteoritics and Planetary Science, 2009, 44, 1323-1330.

12 L. E. Snyder, F. J. Lovas, J. M. Hollis, D. N. Friedel, P. R. Jewell, A. Remijan, V. V. Ilyushin, E. A. Alekseev and S. F. Dyubko, ApJ, 2005, 619, 914-930.

13 P. A. Jones, M. R. Cunningham, P. D. Godfrey and D. M. Cragg, MNRAS, 2007, 374, 579-589.

14 M. R. Cunningham, P. A. Jones, P. D. Godfrey, D. M. Cragg, I. Bains, M. G. Burton, P. Calisse, N. H. M. Crighton, S. J. Curran, T. M. Davis, J. T. Dempsey, B. Fulton, M. G. Hidas, T. Hill, L. Kedziora-Chudczer, V. Minier, M. B. Pracy, C. Purcell, J. Shobbrook and T. Travouillon, MNRAS, 2007, 376, 1201-1210.

15 J. M. Hollis, F. J. Lovas and P. R. Jewell, ApJ, 2000, 540, L107-L110.

16 J. M. Hollis, F. J. Lovas, A. J. Remijan, P. R. Jewell, V. V. Ilyushin and I. Kleiner, ApJ, 2006, 643, L25-L28.

17 A. Belloche, K. M. Menten, C. Comito, H. S. P. Müller, P. Schilke, J. Ott, S. Thorwirth and C. Hieret, A\&A, 2008, 482, 179-196.

18 A. Belloche, R. T. Garrod, H. S. P. Müller, K. M. Menten, C. Comito and P. Schilke, A\&A, 2009, 499, $215-232$.

19 P. Hily-Blant, D. Teyssier, S. Philipp and R. Güsten, A\&A, 2005, 440, 909-919.

20 J. Pety, D. Teyssier, D. Fossé, M. Gerin, E. Roueff, A. Abergel, E. Habart and J. Cernicharo, A\&A, 2005, 435, 885-899.

21 M. Gerin, J. R. Goicoechea, J. Pety and P. Hily-Blant, A\&A, 2009, 494, 977-985.

22 V. Guzmán, J. Pety, P. Gratier, J. R. Goicoechea, M. Gerin, E. Roueff and D. Teyssier, A\&A, 2012, 543, L1.

23 J. Pety, J. R. Goicoechea, P. Hily-Blant, M. Gerin and D. Teyssier, A\&A, 2007, 464, L41-L44.

24 V. V. Guzman, J. R. Goicoechea, J. Pety, P. Gratier, M. Gerin, E. Roueff, F. Le Petit, J. Le Bourlot and A. Faure, ArXive-prints, 2013.

25 S. E. Cummins, R. A. Linke and P. Thaddeus, ApJS, 1986, 60, 819-878. 
26 G. A. Blake, E. C. Sutton, C. R. Masson and T. G. Phillips, ApJ, 1987, 315, 621-645.

27 S. E. Bisschop, J. K. Jørgensen, E. F. van Dishoeck and E. B. M. de Wachter, A\&A, 2007, 465, 913-929.

28 E. F. van Dishoeck, G. A. Blake, D. J. Jansen and T. D. Groesbeck, ApJ, 1995, 447, 760.

29 S. Cazaux, A. G. G. M. Tielens, C. Ceccarelli, A. Castets, V. Wakelam, E. Caux, B. Parise and D. Teyssier, ApJ, 2003, 593, L51-L55.

30 E. Herbst and E. F. van Dishoeck, ARA\&A, 2009, 47, 427-480.

31 D. Teyssier, D. Fossé, M. Gerin, J. Pety, A. Abergel and E. Roueff, A\&A, 2004, 417, 135-149.

32 M. Agúndez, J. Cernicharo, M. Guélin, M. Gerin, M. C. McCarthy and P. Thaddeus, A\&A, 2008, 478, L19-L22.

33 J. R. Goicoechea, J. Pety, M. Gerin, D. Teyssier, E. Roueff, P. Hily-Blant and S. Baek, A\&A, 2006, 456, 565-580.

34 J. R. Goicoechea, J. Pety, M. Gerin, P. Hily-Blant and J. Le Bourlot, A\&A, 2009, 498, 771-783.

35 J. Pety, P. Gratier, V. Guzmán, E. Roueff, M. Gerin, J. R. Goicoechea, S. Bardeau, A. Sievers, F. Le Petit, J. Le Bourlot, A. Belloche and D. Talbi, $A \& A, 2012, \mathbf{5 4 8}, \mathrm{A} 68$

36 V. Guzmán, J. Pety, J. R. Goicoechea, M. Gerin and E. Roueff, A\&A, 2011, 534, A49.

37 P. Gratier, J. Pety, V. Guzmán, M. Gerin, J. R. Goicoechea, E. Roueff and A. Faure, A\&A, 2013, 557, A101.

38 K. I. Öberg, M. D. Boamah, E. C. Fayolle, R. T. Garrod, C. J. Cyganowski and F. van der Tak, ApJ, 2013, 771, 95.

39 A. Bacmann, V. Taquet, A. Faure, C. Kahane and C. Ceccarelli, A\&A, 2012, 541, L12.

40 H. E. Matthews, P. Friberg and W. M. Irvine, ApJ, 1985, 290, 609-614.

41 W. M. Irvine, P. Friberg, N. Kaifu, K. Kawaguchi, Y. Kitamura, H. E. Matthews, Y. Minh, S. Saito, N. Ukita and S. Yamamoto, ApJ, 1989, 342, 871-875.

42 S. Muller, A. Beelen, M. Guélin, S. Aalto, J. H. Black, F. Combes, S. J. Curran, P. Theule and S. N. Longmore, A\&A, 2011,535, A103.

43 A. A. Penzias and C. A. Burrus, ARA\&A, 1973, 11, 51-+

44 D. A. Neufeld, P. Schilke, K. M. Menten, M. G. Wolfire, J. H. Black, F. Schuller, H. S. P. Müller, S. Thorwirth, R. Güsten and S. Philipp, $A \& A, 2006$, 454, L37-L40.

45 D. A. Neufeld, M. G. Wolfire and P. Schilke, ApJ, 2005, 628, 260-274.

46 P. Sonnentrucker, D. A. Neufeld, T. G. Phillips, M. Gerin, D. C. Lis, M. de Luca, J. R. Goicoechea, J. H. Black, T. A. Bell, F. Boulanger, J. Cernicharo, A. Coutens, E. Dartois, M. Kaźmierczak, P. Encrenaz, E. Falgarone, T. R. Geballe, T. Giesen, B. Godard, P. F. Goldsmith, C. Gry, H. Gupta, P. Hennebelle, E. Herbst, P. Hily-Blant, C. Joblin, R. Kołos, J. Krełowski, J. Martín-Pintado, K. M. Menten, R. Monje, B. Mookerjea, J. Pearson, M. Perault, C. M. Persson, R. Plume, M. Salez, S. Schlemmer, M. Schmidt, J. Stutzki, D. Teyssier, C. Vastel, S. Yu, E. Caux, R. Güsten, W. A. Hatch, T. Klein, I. Mehdi, P. Morris and J. S. Ward, A\&A, 2010, 521, L12.

47 M. Asplund, N. Grevesse, A. J. Sauval and P. Scott, ARA\&A, 2009, 47, 481-522.

48 T. P. Snow, J. D. Destree and A. G. Jensen, ApJ, 2007, 655, 285-298.

49 V. Guzmán, E. Roueff, J. Gauss, J. Pety, P. Gratier, J. R. Goicoechea, M. Gerin and D. Teyssier, A\&A, 2012,548, A94.

50 A. Fuente, A. Rodrıguez-Franco, S. Garcia-Burillo, J. Martın-Pintado and J. H. Black, A\&A, 2003, 406, 899-913.

51 O. Berné, C. Joblin, Y. Deville, J. D. Smith, M. Rapacioli, J. P. Bernard, J. Thomas, W. Reach and A. Abergel, A\&A, 2007, 469, 575-586.

52 P. Pilleri, J. Montillaud, O. Berné and C. Joblin, A\&A, 2012, 542, A69.

53 B. A. McGuire, P. B. Carroll, R. A. Loomis, G. A. Blake, J. M. Hollis, F. J. Lovas, P. R. Jewell and A. J. Remijan, ArXiv e-prints, 2013.

54 X. Huang, R. C. Fortenberry and T. J. Lee, ApJ, 2013, 768, L25.

55 R. C. Fortenberry, X. Huang, T. D. Crawford and T. J. Lee, ApJ, 2013, 772, 39.

56 B. A. McGuire, P. B. Carroll, P. Gratier, V. Guzmán, J. Pety, E. Roueff, M. Gerin, G. A. Blake and A. J. Remijan, ApJ, $2014,783,36$.

57 M. P. Bernstein, J. P. Dworkin, S. A. Sandford, G. W. Cooper and L. J. Allamandola, Nature, 2002, 416, $401-403$.

58 G. M. Muñoz Caro, U. J. Meierhenrich, W. A. Schutte, B. Barbier, A. Arcones Segovia, H. Rosenbauer, W. H.-P. Thiemann, A. Brack and J. M. Greenberg, Nature, 2002, 416, 403-406.

59 R. T. Garrod, S. L. W. Weaver and E. Herbst, ApJ, 2008, 682, 283-302.

60 J. G. Mangum and A. Wootten, ApJS, 1993, 89, 123-153.

61 S. Leurini, P. Schilke, K. M. Menten, D. R. Flower, J. T. Pottage and L.-H. Xu, A\&A, 2004, 422, $573-585$.

62 J. G. Mangum, J. Darling, C. Henkel and K. M. Menten, ApJ, 2013, 766, 108.

63 C. R. Purcell, R. Balasubramanyam, M. G. Burton, A. J. Walsh, V. Minier, M. R. Hunt-Cunningham, L. L. Kedziora-Chudczer, S. N. Longmore, T. Hill, I. Bains, P. J. Barnes, A. L. Busfield, P. Calisse, N. H. M. Crighton, S. J. Curran, T. M. Davis, J. T. Dempsey, G. Derragopian, B. Fulton, M. G. Hidas, M. G. Hoare, J.-K. Lee, E. F. Ladd, S. L. Lumsden, T. J. T. Moore, M. T. Murphy, R. D. Oudmaijer, M. B. Pracy, J. Rathborne, S. Robertson, A. S. B. Schultz, J. Shobbrook, P. A. Sparks, J. Storey and T. Travouillion, MNRAS, 2006, 367, 553-576.

64 H. S. P. Müller, S. Thorwirth, D. A. Roth and G. Winnewisser, A\&A, 2001, 370, L49-L52.

65 H. M. Pickett, R. L. Poynter, E. A. Cohen, M. L. Delitsky, J. C. Pearson and H. S. P. Müller, J. Quant. Spec. Radiat. Transf., 1998, 60, $883-890$.

66 H. Kim, R. Keller and W. D. Gwinn, J. Chem. Phys., 1962, 37, 2748-2750.

67 N. B. Hannay and C. P. Smyth, J Am Chem Soc., 1946, 68, 2408-2409.

68 I. Kleiner, F. J. Lovas and M. Godefroid, Journal of Physical and Chemical Reference Data, 1996, 25, 1113-1210.

69 P. M. Burrell, E. Bjarnov and R. H. Schwendeman, Journal of Molecular Spectroscopy, 1980, 82, $193-201$.

70 R. L. Hudson and M. J. Loeffler, ApJ, 2013, 773, 109.

71 M. D. Ward and S. D. Price, ApJ, 2011, 741, 121.

72 J. V. Keane, A. G. G. M. Tielens, A. C. A. Boogert, W. A. Schutte and D. C. B. Whittet, A\&A, 2001, 376, 254-270.

73 A. G. G. M. Tielens and W. Hagen, $A \& A, 1982,114,245-260$.

74 R. Garrod, I. H. Park, P. Caselli and E. Herbst, Faraday Discussions, 2006, 133, 51.

75 S. Ioppolo, H. M. Cuppen, E. F. van Dishoeck and H. Linnartz, MNRAS, 2011, 410, 1089-1095.

76 V. Vinogradoff, F. Duvernay, G. Danger, P. Theulé, F. Borget and T. Chiavassa, A\&A, 2013, 549, A40.

77 F. Mispelaer, P. Theulé, H. Aouididi, J. Noble, F. Duvernay, G. Danger, P. Roubin, O. Morata, T. Hasegawa and T. Chiavassa, A\&A, 2013, 555, A13.

78 J. R. Goicoechea, M. Compiègne and E. Habart, ApJ, 2009, 699, L165-L168. 


\section{A Observational tables}

Table 4 Observation parameters of the deep integrations of the HCOOH lines detected toward the PDR and dense core.

\begin{tabular}{|c|c|c|c|c|c|c|c|c|c|c|c|}
\hline Molecule & Transition & $\begin{array}{r}v \\
\mathrm{GHz}\end{array}$ & $\begin{array}{c}E_{u} \\
\mathrm{~K}\end{array}$ & $\begin{array}{l}A_{u l} \\
\mathrm{~s}^{-1}\end{array}$ & $g_{u}$ & $\begin{array}{l}\text { Line area } \\
\mathrm{mKkms}^{-1}\end{array}$ & $\begin{array}{l}\text { Velocity } \\
\mathrm{kms}^{-1}\end{array}$ & $\begin{array}{l}\text { FWHM } \\
\mathrm{kms}^{-1}\end{array}$ & $\begin{array}{r}T_{\text {peak }} \\
\mathrm{mK}\end{array}$ & $\begin{array}{r}\text { RMS } \\
\mathrm{mK}\end{array}$ & Peak S/N \\
\hline \multicolumn{12}{|c|}{ PDR } \\
\hline $\mathrm{t}-\mathrm{HCOOH}$ & $4_{14}-3_{13}$ & 86.546 & 13.6 & $6.0 \times 10^{-6}$ & 9 & $14.3 \pm 2.5$ & 10.63 & 0.41 & 32.6 & 6.0 & 5 \\
\hline $\mathrm{t}-\mathrm{HCOOH}$ & $4_{04}-3_{03}$ & 89.579 & 10.8 & $7.0 \times 10^{-6}$ & 9 & $13.9 \pm 2.6$ & 10.74 & 0.58 & 22.6 & 5.8 & 4 \\
\hline $\mathrm{t}-\mathrm{HCOOH}$ & $4_{22}-3_{21}$ & 90.165 & 23.5 & $6.0 \times 10^{-6}$ & 9 & $10.2 \pm 2.2$ & 10.91 & 0.51 & 18.7 & 5.4 & 3 \\
\hline $\mathrm{t}-\mathrm{HCOOH}$ & $4_{13}-3_{12}$ & 93.098 & 14.4 & $8.0 \times 10^{-6}$ & 9 & $10.8 \pm 2.4$ & 10.54 & 0.51 & 19.7 & 6.0 & 3 \\
\hline $\mathrm{t}-\mathrm{HCOOH}$ & $5_{15}-4_{14}$ & 108.127 & 18.8 & $1.3 \times 10^{-5}$ & 11 & $11.3 \pm 2.9$ & 10.83 & 0.38 & 27.7 & 9.8 & 3 \\
\hline $\mathrm{t}-\mathrm{HCOOH}$ & $5_{05}-4_{04}$ & 111.747 & 16.1 & $1.4 \times 10^{-5}$ & 11 & $13.2 \pm 5.1$ & 10.82 & 0.41 & 30.0 & 9.3 & 3 \\
\hline $\mathrm{t}-\mathrm{HCOOH}$ & $616-515$ & 129.672 & 25.0 & $2.2 \times 10^{-5}$ & 13 & $17.8 \pm 4.1$ & 10.66 & 0.40 & 42.1 & 13.2 & 3 \\
\hline $\mathrm{t}-\mathrm{HCOOH}$ & $6_{06}-5_{05}$ & 133.767 & 22.5 & $2.5 \times 10^{-5}$ & 13 & $17.1 \pm 3.9$ & 10.57 & 0.36 & 45.2 & 14.1 & 3 \\
\hline $\mathrm{t}-\mathrm{HCOOH}$ & $6_{24}-5_{23}$ & 135.738 & 35.4 & $2.3 \times 10^{-5}$ & 13 & $16.1 \pm 3.5$ & 10.46 & 0.30 & 49.9 & 13.9 & 4 \\
\hline \multicolumn{12}{|c|}{ CORE } \\
\hline $\mathrm{t}-\mathrm{HCOOH}$ & $4_{04}-3_{03}$ & 89.579 & 10.8 & $7.0 \times 10^{-6}$ & 9 & $17.2 \pm 2.8$ & 10.56 & 0.59 & 27.4 & 6.2 & 4 \\
\hline $\mathrm{t}-\mathrm{HCOOH}$ & $4_{13}-3_{12}$ & 93.098 & 14.4 & $8.0 \times 10^{-6}$ & 9 & $11.4 \pm 2.6$ & 10.64 & 0.34 & 31.4 & 6.5 & 5 \\
\hline $\mathrm{t}-\mathrm{HCOOH}$ & $5_{15}-4_{14}$ & 108.127 & 18.8 & $1.3 \times 10^{-5}$ & 11 & $16.3 \pm 3.5$ & 10.61 & 0.38 & 40.1 & 9.9 & 4 \\
\hline $\mathrm{t}-\mathrm{HCOOH}$ & $5_{05}-4_{04}$ & 111.747 & 16.1 & $1.4 \times 10^{-5}$ & 11 & $11.5 \pm 3.1$ & 10.54 & 0.30 & 36.3 & 9.0 & 4 \\
\hline $\mathrm{t}-\mathrm{HCOOH}$ & $6_{06}-5_{05}$ & 133.767 & 22.5 & $2.5 \times 10^{-5}$ & 13 & $26.2 \pm 5.6$ & 10.39 & 0.44 & 55.9 & 13.5 & 4 \\
\hline
\end{tabular}

Note: All temperatures are given in the main beam temperature scale.

Table 5 Observation parameters of the deep integrations of the $\mathrm{CH}_{2} \mathrm{CO}$ lines detected toward the PDR and dense core.

\begin{tabular}{|c|c|c|c|c|c|c|c|c|c|c|c|}
\hline Molecule & Transition & $\begin{array}{r}v \\
\mathrm{GHz}\end{array}$ & $\begin{array}{r}E_{u} \\
\mathrm{~K}\end{array}$ & $\begin{array}{l}A_{u l} \\
\mathrm{~s}^{-1}\end{array}$ & $g_{u}$ & $\begin{array}{l}\text { Line area } \\
\mathrm{mKkm} \mathrm{s}^{-1}\end{array}$ & $\begin{array}{l}\text { Velocity } \\
\mathrm{kms}^{-1}\end{array}$ & $\begin{array}{l}\text { FWHM } \\
\mathrm{km} \mathrm{s}^{-1}\end{array}$ & $\begin{array}{r}T_{\text {peak }} \\
\mathrm{mK}\end{array}$ & $\begin{array}{r}\text { RMS } \\
\mathrm{mK}\end{array}$ & Peak S/N \\
\hline \multicolumn{12}{|c|}{ PDR } \\
\hline $\mathrm{o}-\mathrm{CH}_{2} \mathrm{CO}$ & $4_{13}-3_{12}$ & 81.586 & 22.9 & $5.0 \times 10^{-6}$ & 27 & $83.1 \pm 10.7$ & 10.62 & 0.69 & 113.4 & 19.8 & 6 \\
\hline $\mathrm{o}-\mathrm{CH}_{2} \mathrm{CO}$ & $5_{15}-4_{14}$ & 100.095 & 27.5 & $1.0 \times 10^{-5}$ & 33 & $87.9 \pm 3.6$ & 10.70 & 0.64 & 128.7 & 7.4 & 17 \\
\hline $\mathrm{o}-\mathrm{CH}_{2} \mathrm{CO}$ & $5_{14}-4_{13}$ & 101.981 & 27.8 & $1.1 \times 10^{-5}$ & 33 & $89.0 \pm 3.2$ & 10.67 & 0.65 & 127.7 & 7.1 & 18 \\
\hline $\mathrm{o}-\mathrm{CH}_{2} \mathrm{CO}$ & $7_{17}-6_{16}$ & 140.127 & 40.0 & $2.9 \times 10^{-5}$ & 45 & $77.9 \pm 4.7$ & 10.66 & 0.55 & 133.0 & 12.4 & 11 \\
\hline $\mathrm{o}-\mathrm{CH}_{2} \mathrm{CO}$ & $7_{16}-6_{15}$ & 142.769 & 40.5 & $3.1 \times 10^{-5}$ & 45 & $68.4 \pm 8.1$ & 10.66 & 0.47 & 135.3 & 25.6 & 5 \\
\hline $\mathrm{o}-\mathrm{CH}_{2} \mathrm{CO}$ & $8_{18}-7_{17}$ & 160.142 & 47.6 & $4.5 \times 10^{-5}$ & 51 & $102.7 \pm 13.5$ & 10.74 & 0.72 & 134.2 & 35.7 & 4 \\
\hline $\mathrm{o}-\mathrm{CH}_{2} \mathrm{CO}$ & $10_{19}-9_{18}$ & 203.940 & 66.9 & $9.3 \times 10^{-5}$ & 63 & $45.9 \pm 7.0$ & 10.72 & 0.67 & 64.8 & 10.6 & 6 \\
\hline $\mathrm{p}-\mathrm{CH}_{2} \mathrm{CO}$ & $5_{05}-4_{04}$ & 101.037 & 14.5 & $1.1 \times 10^{-5}$ & 11 & $45.3 \pm 3.1$ & 10.81 & 0.70 & 60.8 & 6.8 & 9 \\
\hline $\mathrm{p}-\mathrm{CH}_{2} \mathrm{CO}$ & $7_{07}-6_{06}$ & 141.438 & 27.2 & $3.1 \times 10^{-5}$ & 15 & $42.9 \pm 6.7$ & 10.67 & 0.56 & 71.6 & 17.9 & 4 \\
\hline $\mathrm{o}-\mathrm{CH}_{2} \mathrm{CO}^{c}$ & $5_{33}-4_{32}{ }^{a}$ & 101.002 & 132.8 & $7.0 \times 10^{-6}$ & 33 & $31.0 \pm 4.5$ & 10.98 & 0.87 & 33.6 & 8.5 & 4 \\
\hline $\mathrm{o}-\mathrm{CH}_{2} \mathrm{CO}^{c}$ & $7_{35}-6_{34}^{b}$ & 141.402 & 145.4 & $2.5 \times 10^{-5}$ & 45 & $50.2 \pm 8.0$ & 10.28 & 1.03 & 45.9 & 16.9 & 3 \\
\hline $\mathrm{o}-\mathrm{CH}_{2} \mathrm{CO}^{c}$ & $7_{25}-6_{24}$ & 141.452 & 79.5 & $2.8 \times 10^{-5}$ & 15 & $39.1 \pm 6.9$ & 10.48 & 0.83 & 44.4 & 15.7 & 3 \\
\hline \multicolumn{12}{|c|}{ CORE } \\
\hline $\mathrm{o}-\mathrm{CH}_{2} \mathrm{CO}$ & $4_{13}-3_{12}$ & 81.586 & 22.9 & $5.0 \times 10^{-6}$ & 27 & $34.3 \pm 8.6$ & 10.86 & 0.69 & 47.0 & 17.8 & 3 \\
\hline $\mathrm{o}-\mathrm{CH}_{2} \mathrm{CO}$ & $5_{15}-4_{14}$ & 100.095 & 27.5 & $1.0 \times 10^{-5}$ & 33 & $38.9 \pm 3.3$ & 10.67 & 0.52 & 70.7 & 7.8 & 9 \\
\hline $\mathrm{o}-\mathrm{CH}_{2} \mathrm{CO}$ & $5_{14}-4_{13}$ & 101.981 & 27.8 & $1.1 \times 10^{-5}$ & 33 & $33.3 \pm 3.2$ & 10.65 & 0.47 & 66.6 & 7.8 & 9 \\
\hline $\mathrm{o}-\mathrm{CH}_{2} \mathrm{CO}$ & $7_{17}-6_{16}$ & 140.127 & 40.0 & $2.9 \times 10^{-5}$ & 45 & $30.6 \pm 4.2$ & 10.60 & 0.51 & 56.5 & 11.8 & 5 \\
\hline $\mathrm{p}-\mathrm{CH}_{2} \mathrm{CO}$ & $5_{05}-4_{04}$ & 101.037 & 14.5 & $1.1 \times 10^{-5}$ & 11 & $29.5 \pm 3.9$ & 10.68 & 0.73 & 37.7 & 8.0 & 5 \\
\hline $\mathrm{p}-\mathrm{CH}_{2} \mathrm{CO}$ & $7_{07}-6_{06}$ & 141.438 & 27.2 & $3.1 \times 10^{-5}$ & 15 & $31.1 \pm 7.0$ & 10.68 & 0.69 & 42.5 & 17.0 & 3 \\
\hline
\end{tabular}

Note: All temperatures are given in the main beam temperature scale.

${ }^{a}$ Blended with the $5_{32}-4_{31}$ line.

${ }^{b}$ Blended with the $7_{34}-6_{33}$ line.

$c$ The line identification is uncertain. 
Table 6 Observation parameters of the deep integrations of the $\mathrm{CH}_{3} \mathrm{CHO}$ lines detected toward the PDR and dense core.

\begin{tabular}{|c|c|c|c|c|c|c|c|c|c|c|c|}
\hline Molecule & Transition & $\begin{array}{r}v \\
\mathrm{GHz}\end{array}$ & $\begin{array}{c}E_{u} \\
\mathrm{~K}\end{array}$ & $\begin{array}{l}A_{u l} \\
\mathrm{~s}^{-1}\end{array}$ & $g_{u}$ & $\begin{array}{l}\text { Line area } \\
\mathrm{mKkm} \mathrm{s}^{-1}\end{array}$ & $\begin{array}{l}\text { Velocity } \\
\mathrm{kms}^{-1}\end{array}$ & $\begin{array}{c}\text { FWHM } \\
\mathrm{kms}^{-1}\end{array}$ & $\begin{array}{r}T_{\text {peak }} \\
\mathrm{mK}\end{array}$ & $\begin{array}{r}\text { RMS } \\
\mathrm{mK}\end{array}$ & Peak S/N \\
\hline \multicolumn{12}{|c|}{ PDR } \\
\hline $\mathrm{CH}_{3} \mathrm{CHO}-\mathrm{E}$ & $5_{15}-4_{14}$ & 93.595 & 15.8 & $2.5 \times 10^{-5}$ & 22 & $57.5 \pm 2.5$ & 10.75 & 0.63 & 86.0 & 5.2 & 16 \\
\hline $\mathrm{CH}_{3} \mathrm{CHO}-\mathrm{E}$ & $5_{05}-4_{04}$ & 95.947 & 13.9 & $2.8 \times 10^{-5}$ & 22 & $81.6 \pm 3.0$ & 10.67 & 0.68 & 113.5 & 6.1 & 19 \\
\hline $\mathrm{CH}_{3} \mathrm{CHO}-\mathrm{E}$ & $5_{14}-4_{13}$ & 98.863 & 16.6 & $3.0 \times 10^{-5}$ & 22 & $68.2 \pm 3.5$ & 10.68 & 0.61 & 104.7 & 8.0 & 13 \\
\hline $\mathrm{CH}_{3} \mathrm{CHO}-\mathrm{E}$ & $6_{16}-5_{15}$ & 112.254 & 21.2 & $4.5 \times 10^{-5}$ & 26 & $41.8 \pm 4.1$ & 10.59 & 0.47 & 83.4 & 11.1 & 8 \\
\hline $\mathrm{CH}_{3} \mathrm{CHO}-\mathrm{E}$ & $6_{06}-5_{05}$ & 114.940 & 19.4 & $5.2 \times 10^{-5}$ & 26 & $88.2 \pm 15.3$ & 10.65 & 0.67 & 124.3 & 32.0 & 4 \\
\hline $\mathrm{CH}_{3} \mathrm{CHO}-\mathrm{E}$ & $7_{07}-6_{06}$ & 133.831 & 25.9 & $8.2 \times 10^{-5}$ & 30 & $36.2 \pm 7.4$ & 10.70 & 0.83 & 41.0 & 16.6 & 2 \\
\hline $\mathrm{CH}_{3} \mathrm{CHO}-\mathrm{E}$ & $7_{16}-6_{15}$ & 138.285 & 28.9 & $8.6 \times 10^{-5}$ & 30 & $30.6 \pm 4.7$ & 10.60 & 0.52 & 54.9 & 14.5 & 4 \\
\hline $\mathrm{CH}_{3} \mathrm{CHO}-\mathrm{E}$ & $8_{18}-7_{17}$ & 149.505 & 34.7 & $1.1 \times 10^{-4}$ & 34 & $20.5 \pm 4.2$ & 10.81 & 0.33 & 59.1 & 16.8 & 4 \\
\hline $\mathrm{CH}_{3} \mathrm{CHO}-\mathrm{A}$ & $5,-4_{14}$ & 93.581 & 15.7 & $2.5 \times 10^{-5}$ & 22 & $44.3 \pm 2.6$ & 10.66 & 0.54 & 76.9 & 6.0 & 13 \\
\hline $\mathrm{CH}_{3} \mathrm{CHO}-\mathrm{A}$ & $5_{05}-4_{04}$ & 95.963 & 13.8 & $2.8 \times 10^{-5}$ & 22 & $73.1 \pm 2.8$ & 10.70 & 0.63 & 108.5 & 5.8 & 19 \\
\hline $\mathrm{CH}_{3} \mathrm{CHO}-\mathrm{A}$ & $5_{24}-4_{23}$ & 96.274 & 22.9 & $2.4 \times 10^{-5}$ & 22 & $13.5 \pm 2.3$ & 10.55 & 0.48 & 26.7 & 5.6 & 5 \\
\hline $\mathrm{CH}_{3} \mathrm{CHO}-\mathrm{A}$ & $5_{23}-4_{22}$ & 96.633 & 23.0 & $2.4 \times 10^{-5}$ & 22 & $12.3 \pm 1.9$ & 10.68 & 0.41 & 28.5 & 5.1 & 6 \\
\hline $\mathrm{CH}_{3} \mathrm{CHO}-\mathrm{A}$ & $5_{14}-4_{13}$ & 98.901 & 16.5 & $3.0 \times 10^{-5}$ & 22 & $73.8 \pm 3.4$ & 10.73 & 0.62 & 112.7 & 7.7 & 15 \\
\hline $\mathrm{CH}_{3} \mathrm{CHO}-\mathrm{A}$ & $6_{16}-5_{15}$ & 112.249 & 21.1 & $4.5 \times 10^{-5}$ & 26 & $56.0 \pm 5.1$ & 10.68 & 0.69 & 76.3 & 11.4 & 7 \\
\hline $\mathrm{CH}_{3} \mathrm{CHO}-\mathrm{A}$ & $6_{06}-5_{05}$ & 114.960 & 19.4 & $5.0 \times 10^{-5}$ & 26 & $83.6 \pm 13.6$ & 10.71 & 0.67 & 117.5 & 28.8 & 4 \\
\hline $\mathrm{CH}_{3} \mathrm{CHO}-\mathrm{A}$ & $7_{07}-6_{06}$ & 133.854 & 25.8 & $7.9 \times 10^{-5}$ & 30 & $30.8 \pm 3.6$ & 10.61 & 0.39 & 73.9 & 11.9 & 6 \\
\hline $\mathrm{CH}_{3} \mathrm{CHO}-\mathrm{A}$ & $7_{25}-6_{24}$ & 135.685 & 35.0 & $7.9 \times 10^{-5}$ & 30 & $15.4 \pm 3.2$ & 10.76 & 0.29 & 50.5 & 13.2 & 4 \\
\hline $\mathrm{CH}_{3} \mathrm{CHO}-\mathrm{A}$ & $7_{16}-6_{15}$ & 138.320 & 28.8 & $8.6 \times 10^{-5}$ & 30 & $52.9 \pm 6.8$ & 10.74 & 0.49 & 100.6 & 17.0 & 6 \\
\hline \multicolumn{12}{|c|}{ CORE } \\
\hline $\mathrm{CH}_{3} \mathrm{CHO}-\mathrm{E}$ & $5_{15}-4_{14}$ & 93.595 & 15.8 & $2.5 \times 10^{-5}$ & 22 & $34.4 \pm 2.2$ & 10.71 & 0.74 & 43.5 & 4.2 & 10 \\
\hline $\mathrm{CH}_{3} \mathrm{CHO}-\mathrm{E}$ & $5_{05}-4_{04}$ & 95.947 & 13.9 & $2.8 \times 10^{-5}$ & 22 & $38.5 \pm 2.4$ & 10.66 & 0.63 & 57.1 & 5.4 & 10 \\
\hline $\mathrm{CH}_{3} \mathrm{CHO}-\mathrm{E}$ & $5_{14}-4_{13}$ & 98.863 & 16.6 & $3.0 \times 10^{-5}$ & 22 & $26.6 \pm 4.0$ & 10.63 & 0.60 & 41.5 & 8.8 & 5 \\
\hline $\mathrm{CH}_{3} \mathrm{CHO}-\mathrm{A}$ & $5_{15}-4_{14}$ & 93.581 & 15.7 & $2.5 \times 10^{-5}$ & 22 & $26.7 \pm 2.0$ & 10.62 & 0.57 & 44.1 & 4.6 & 10 \\
\hline $\mathrm{CH}_{3} \mathrm{CHO}-\mathrm{A}$ & $5_{05}-4_{04}$ & 95.963 & 13.8 & $2.8 \times 10^{-5}$ & 22 & $33.1 \pm 3.1$ & 10.67 & 0.80 & 38.9 & 5.7 & 7 \\
\hline $\mathrm{CH}_{3} \mathrm{CHO}-\mathrm{A}$ & $5_{14}-4_{13}$ & 98.901 & 16.5 & $3.0 \times 10^{-5}$ & 22 & $35.5 \pm 5.7$ & 10.74 & 0.74 & 44.8 & 9.5 & 5 \\
\hline $\mathrm{CH}_{3} \mathrm{CHO}-\mathrm{A}$ & $6_{16}-5_{15}$ & 112.249 & 21.1 & $4.5 \times 10^{-5}$ & 26 & $16.0 \pm 3.5$ & 10.62 & 0.55 & 27.2 & 9.9 & 3 \\
\hline
\end{tabular}

Note: All temperatures are given in the main beam temperature scale.

Table 7 Observation parameters of the deep integrations of the $\mathrm{CH}_{3} \mathrm{CCH}$ lines detected toward the PDR and dense core.

\begin{tabular}{|c|c|c|c|c|c|c|c|c|c|c|c|}
\hline Molecule & Transition & $\begin{array}{r}v \\
\mathrm{GHz}\end{array}$ & $\begin{array}{c}E_{u} \\
\mathrm{~K}\end{array}$ & $\begin{array}{l}A_{u l} \\
\mathrm{~s}^{-1}\end{array}$ & $g_{u}$ & $\begin{array}{l}\text { Line area } \\
\mathrm{mKkms}^{-1}\end{array}$ & $\begin{array}{c}\text { Velocity } \\
\mathrm{kms}^{-1}\end{array}$ & $\begin{array}{c}\mathrm{FWHM}^{a} \\
\mathrm{kms}^{-1}\end{array}$ & $\begin{array}{r}T_{\text {peak }} \\
\mathrm{mK}\end{array}$ & $\begin{array}{r}\text { RMS } \\
\text { mK }\end{array}$ & Peak S/N \\
\hline & & & & PDR & & & & & & & \\
\hline $\mathrm{CH}_{3} \mathrm{CCH}-\mathrm{E}$ & $5_{1}-4_{1}$ & 85.456 & 19.5 & $5.93 \times 10^{-7}$ & 22 & $15.2 \pm 2.7$ & 10.54 & 0.60 & 23.9 & 6.8 & 3 \\
\hline $\mathrm{CH}_{3} \mathrm{CCH}-\mathrm{E}$ & $61-5_{1}$ & 102.546 & 24.4 & $1.05 \times 10^{-6}$ & 26 & $16.0 \pm 2.7$ & 10.95 & 0.60 & 25.0 & 7.6 & 3 \\
\hline $\mathrm{CH}_{3} \mathrm{CCH}-\mathrm{E}$ & $8_{1}-7_{1}$ & 136.725 & 36.7 & $2.50 \times 10^{-6}$ & 34 & $16.8 \pm 3.7$ & 10.53 & 0.60 & 26.3 & 12.2 & 2 \\
\hline $\mathrm{CH}_{3} \mathrm{CCH}-\mathrm{E}$ & $12_{1}-11_{1}$ & 205.077 & 71.2 & $8.95 \times 10^{-6}$ & 50 & $22.3 \pm 3.7$ & 10.67 & 0.60 & 34.9 & 7.6 & 4 \\
\hline $\mathrm{CH}_{3} \mathrm{CCH}-\mathrm{E}$ & $13_{1}-12_{1}$ & 222.163 & 81.9 & $1.14 \times 10^{-5}$ & 27 & $15.3 \pm 3.8$ & 10.66 & 0.60 & 23.9 & 7.9 & 3 \\
\hline $\mathrm{CH}_{3} \mathrm{CCH}-\mathrm{A}$ & $5_{0}-4_{0}$ & 85.457 & 12.3 & $6.18 \times 10^{-7}$ & 22 & $14.6 \pm 2.3$ & 10.77 & 0.60 & 22.8 & 5.7 & 4 \\
\hline $\mathrm{CH}_{3} \mathrm{CCH}-\mathrm{A}$ & $6_{0}-5_{0}$ & 102.548 & 17.2 & $1.08 \times 10^{-6}$ & 26 & $10.8 \pm 2.7$ & 10.72 & 0.60 & 17.0 & 7.1 & 2 \\
\hline $\mathrm{CH}_{3} \mathrm{CCH}-\mathrm{A}$ & $8_{3}-7_{3}$ & 136.705 & 94.6 & $2.25 \times 10^{-6}$ & 34 & $15.2 \pm 3.7$ & 10.55 & 0.60 & 23.8 & 11.8 & 2 \\
\hline $\mathrm{CH}_{3} \mathrm{CCH}-\mathrm{A}$ & $12_{0}-11_{0}$ & 205.081 & 64.0 & $9.02 \times 10^{-6}$ & 50 & $22.0 \pm 4.0$ & 10.76 & 0.60 & 34.4 & 7.9 & 4 \\
\hline $\mathrm{CH}_{3} \mathrm{CCH}-\mathrm{A}$ & $13_{0}-12_{0}$ & 222.167 & 74.6 & $1.15 \times 10^{-5}$ & 27 & $14.1 \pm 3.7$ & 10.35 & 0.60 & 22.1 & 7.6 & 2 \\
\hline $\mathrm{CH}_{3} \mathrm{CCH}-\mathrm{A}$ & $14_{3}-13_{3}$ & 239.211 & 151.1 & $9.96 \times 10^{-5}$ & 58 & $28.6 \pm 5.9$ & 10.46 & 0.60 & 44.8 & 12.8 & 3 \\
\hline \multirow[t]{2}{*}{$\mathrm{CH}_{3} \mathrm{CCH}-\mathrm{A}$} & $14_{0}-13_{0}$ & 239.252 & 86.1 & $1.40 \times 10^{-5}$ & 58 & $54.2 \pm 7.5$ & 10.63 & 0.60 & 84.9 & 16.1 & 5 \\
\hline & & & & CORE & & & & & & & \\
\hline $\mathrm{CH}_{3} \mathrm{CCH}-\mathrm{E}$ & $5_{1}-4_{1}$ & 85.456 & 19.5 & $5.93 \times 10^{-7}$ & 22 & $13.5 \pm 1.9$ & 10.48 & 0.50 & 25.4 & 5.5 & 4 \\
\hline $\mathrm{CH}_{3} \mathrm{CCH}-\mathrm{E}$ & $6_{1}-5_{1}$ & 102.546 & 24.4 & $1.05 \times 10^{-6}$ & 26 & $20.0 \pm 2.9$ & 10.48 & 0.50 & 37.6 & 8.9 & 4 \\
\hline $\mathrm{CH}_{3} \mathrm{CCH}-\mathrm{E}$ & $8_{1}-7_{1}$ & 136.725 & 36.7 & $2.50 \times 10^{-6}$ & 34 & $27.4 \pm 4.0$ & 10.56 & 0.50 & 51.6 & 14.2 & 3 \\
\hline $\mathrm{CH}_{3} \mathrm{CCH}-\mathrm{A}$ & $5_{0}-4_{0}$ & 85.457 & 12.3 & $6.18 \times 10^{-7}$ & 22 & $16.8 \pm 2.4$ & 10.59 & 0.50 & 31.5 & 6.3 & 4 \\
\hline $\mathrm{CH}_{3} \mathrm{CCH}-\mathrm{A}$ & $6_{0}-5_{0}$ & 102.548 & 17.2 & $1.08 \times 10^{-6}$ & 26 & $25.7 \pm 2.8$ & 10.74 & 0.50 & 48.2 & 8.5 & 5 \\
\hline
\end{tabular}

Note: All temperatures are given in the main beam temperature scale.

${ }^{a}$ The line width was fixed to guide the Gaussian fit at low signal-to-noise ratio. 